\title{
Development and evaluation of an internet-based treatment for generalized anxiety disorder
} An acceptance-based approach

Mats Dahlin

\section{LINKÖPING UNIVERSITY}




\title{
Development and evaluation of an internet-based treatment for generalized anxiety disorder
}

\section{An acceptance-based approach}

\author{
Mats Dahlin
}

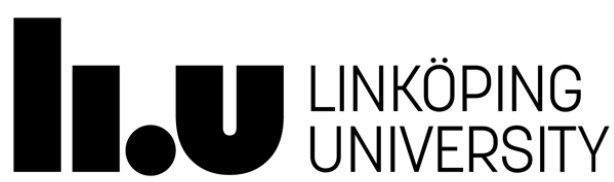

Linköping Studies in Arts and Sciences No. 794

Linköping Studies in Behavioural Science No. 221

Faculty of Arts and Sciences

Linköping 2020 
Linköping Studies in Arts and Sciences • No. 794

Linköping Studies in Behavioural Science $\cdot$ No. 221

At the Faculty of Arts and Sciences at Linköping University, research and doctoral studies are carried out within broad problem areas. Research is organized in interdisciplinary research environments and doctoral studies mainly in graduate schools. Jointly, they publish the series Linköping Studies in Arts and Sciences. This thesis comes from the Division of Psychology at the Department of Behavioural Sciences and Learning.

Distributed by:

Department of Behavioural Sciences and Learning

Linköping University

58183 Linköping

Mats Dahlin

Development and evaluation of an internet-based treatment for generalized anxiety disorder:

An acceptance-based approach

Edition 1:1

ISBN 978-91-7929-793-0

ISSN 0282-9800

ISSN 1654-2029

CMats Dahlin

Department of Behavioural Sciences and Learning, 2020

Cover photography by: Magnus Stalby

Printed by: LiU-Tryck, Linköping 2020 


\section{Acknowledgements}

Ni är många som varit med på den resa som lett fram till den här avhandlingen. En del av er genom ert engagemang i allt arbete som ligger bakom en avhandling. Andra för att ni är en del av mitt liv och därigenom påverkat den jag är och vad jag gör. Tack till er alla för att ni finns i mitt liv!

Särskilda tack vill jag rikta till...

Min huvudhandledare Gerhard Andersson för all den tid, kunskap och tilltro som du har fyllt mitt liv med sedan jag sökte upp dig som psykologstudent och ville göra ett examensarbete. Det har blivit många lärorika och inspirerande år med samarbeten, artiklar och till slut en avhandling. Jag ser fram mot fler spännande samarbeten och lärdomar även efter detta.

Min bihandledare Per Carlbring för din entusiasm, energi och blixtsnabba arbete i alla de studier vi gjort tillsammans. Utan dig skulle det vara mycket tråkigare att forska!

Erik Andersson för din inspirerande insats som opponent på mitt halvtidsseminarium. Det var verkligen en positiv injektion i arbetet med avhandlingen.

Alexander Rozental för din värdefulla feedback i egenskap av opponent på slutseminariet. Tack vare dig känner jag mig bättre rustad för disputationen, något jag är mycket tacksam för.

Min opponent på disputationen, Rikard Wicksell. Tack för ditt engagemang! 
Alla forskarkollegor och doktorander som jag stött på genom åren. Ni har alla berikat min tillvaro och forskning. Jag vill även specifikt tacka Matilda Berg för din glädje, närvaro och nyfikenhet i våra samtal, du har verkligen haft en positiv inverkan på min tid som doktorand. Tack Örn Kolbeinsson och Anton Käll för alla stimulerande samtal och att ni delat med er av er kunskap om metod. Tack Tomas Lindegaard för spännande samtal om olika perspektiv i behandling.

Alla som arbetat i studierna och medförfattare. Utan er Marielle Ryberg, Karin Angantyr, Nina Annas, Kristoffer Magnusson, Tomas Johansson, Johan Sjögren, Magnus Pettersson, Asa Kadowaki, Pim Cuijpers, Andreas Johansson, Harry Romare och George Vlaescu hade studierna inte varit möjliga att genomföra. Jag vill även rikta ett särskilt tack till Andreas Håkansson för ditt ovärderliga engagemang i förarbetet och genomförandet av studie III.

Kursansvariga, lärare och administratörer som varit en del av min doktorandtid. Ett särskilt tack vill jag rikta till Britt-Marie Alfredsson för att du med trevlig och guidande hand har informerat, påmint och underlättat allt det praktiska med att vara doktorand och att skriva avhandling. Det har varit ovärderligt.

Kristofer Vernmark för all din klokhet, värme och engagemang. Finare vän och kollega kan man inte hitta. Ett extra tack för ditt engagemang $\mathrm{i}$ min forskning och all hjälp med kappan. Snart är lillebrorsan också doktor.

Magnus Stalby, min jämtlandsbroder. Din generositet och vänskap berikar mig på så många sätt. Jag är så glad över att ha en av dina bilder på avhandlingens omslag.

Hanna Stalby för att du finns nära och engagerat i både framgång och motgång. Det känns fint att veta att jag alltid kan vända mig till dig när jag vill dela något med en vän. 
Tomas Lindin för alla intellektuella utmaningar som jag får av våra samtal. Du hjälper mig vara en bättre psykolog och forskare.

Alberto Santi för din fina vänskap. Alla stimulerande och utvecklande samtal vi har om behandling, inlärningsteori och att vara psykolog gör mig visare.

Marielle Ryberg för att du är du. Din värme och omtänksamhet betyder mycket för mig och min familj.

Therese Andersson för att du är en fin vän och modell i yrkeslivet. Oavsett vad som händer i mitt liv så vet jag att du finns där med tröstande ord, stimulerande utmaningar eller en knäpp på näsan om det behövs.

Sara Hillbom och andra på Psykologpartners som gjort det möjligt för mig att arbeta med avhandlingen och doktorera. Tack även alla andra partnerskollegor som inspirerar, utmanar och får mig att skratta. Ni är mer än bara arbetskamrater.

Fredrik Malmaeus för alla roliga, varma och inspirerande möten vi haft under arbetet med att utveckla internbaserade behandlingar och i livet utanför jobbet. Ett8 for life!

Jenny Katalinic för alla samtal vi haft genom åren om jobbet, livet och det som inte funkar.

Malin Angberg för utvecklande och inspirerande samtal om TBA och dess tillämpning. Med PBS har vi gjort en skillnad.

Maria Jannert för alla de samtal vi haft om behandling, handledning och livets händelser sedan den dag du tog på dig rollen som PTPhandledare. Du är en inspirerande modell och fin vän. 
Marie Blom för att du hjälpt mig med språket i avhandlingen och gett synpunkter på innehållet. Jag är tacksam för all din hjälp.

Håkan Wisung för din tilltro till mig som blivande psykolog och senare i yrkeslivet. Jag har så mycket att tacka dig för.

Jonas Almlöv min vapendragare och vän. Jag är så glad att vi träffade varandra på intervjuintaget till psykologprogrammet och att du fortfarande är min vän. Få personer har format mina kliniska tankar så mycket som du.

Min kära vän Björn Paxling. Vi har delat så mycket sedan vi lärde känna varandra på psykologprogrammet. Din visdom, omsorg och vilja att utmana gör mig till en bättre person och en bättre psykolog.

Anna Malmquist för alla spännande samtal vi haft om psykologi och livet. Du hjälper mig bredda mina perspektiv, det är jag tacksam för.

Per Bengtsson för att du delar din klokhet, underfundighet och humor med mig. Dina livsbetraktelser berikar mitt liv på ett unikt sätt.

Pedro Westerdahl min kära gamla vän. Utan dig hade jag inte kunnat något om all den underbara konst som berikar livet och ger perspektiv.

Ulrika Birberg Thornberg, Robert, Edvin och Alva för att ni är så fina vänner till mig, Pia och Emmie. Ett särskilt tack till dig Ulrika för all din hjälp jag och familjen fått under tiden jag varit frånvarande och jobbat med avhandlingen.

Kerstin Völker och Geoff Gooch för allt stöd vi får av er och ert engagemang i Emmie. 
Min älskade Pia, det du betyder för mig kan inte fångas med ord. Jag minns när jag flyttade in i din studentkorridor i Umeå och träffade dig för första gången. Det var startskottet för något stort!

Min älskade dotter Emmie. Ingen lär mig så mycket om livet som du. Jag är så glad, stolt och ödmjuk för att du finns hos mig. När allt arbete med avhandlingen är klart ska vi ta igen all lek, dans och mys som inte blivit av för att jag jobbat. Jag ser fram emot disputationsfesten som du är med och ordnar, då ska vi fira med god mat och massor av efterrätt och godis!

Min kära mamma och pappa, finare föräldrar än er kan man inte ha. Tack älskade mamma för all den värme, kärlek och stöttning du gett mig genom livet. Tack älskade pappa för ditt engagemang, omtanke och kärlek. Er tilltro till mig gör mig stark. Det är en gåva jag alltid kommer bära med mig.

Min älskade bror, du betyder så mycket för mig. Genom hela livet har du funnits där med trygghet, värme och glädje. Du, Elin, Alvar och Elsa är så viktiga för mig, Pia och Emmie.

Min fina kusin Jonas för att du, Malin, Matilda och Julia väljer att vara en del av mitt, Pia och Emmies liv. Det betyder mycket för oss.

Gun Enderby, du är en ärlig och fin person. Jag är glad att du blev en del av mitt liv när jag träffade Pia. Du är en fin mormor och vi tycker alla om dig så mycket.

Hans Enderby för alla spännande samtal vi haft och för att du är en så fin morfar.

Slutligen vill jag rikta ett tack till mormor och morfar, Ivan och Aina, faster Margit och farmor och farfar. Ni har alla varit viktiga i mitt liv och jag önskar att jag kunde få dela detta mer er. 



\section{Abstract}

Generalized anxiety disorder (GAD) is a chronic condition characterized by an excessive and uncontrollable worry. GAD has a highly negative impact on all aspects of life, and the costs for society are considerable. Cognitive behaviour therapy (CBT), delivered faceto-face or online, has been shown to be effective in treating GAD. However, there are still room for improvement, with treatment content and format of delivery being two areas to further investigate. Internetbased treatments are often based on a generic CBT model of GAD and include treatment strategies such as cognitive restructuring and relaxation. Furthermore, the impact of therapist support has shown inconclusive results.

Overall, this thesis aimed to evaluate the effects of a new internetbased treatment for GAD, based on acceptance, mindfulness, and valued action, delivered with different types of support. Study I was a small pilot trial with a within-group design. The study included 16 participants diagnosed with GAD who received the newly developed treatment program with weekly therapist support. Statistically significant and large effect sizes were observed on self-rated worry at post-treatment, and the effects were maintained at a three-months follow-up. Study II included 103 participants diagnosed with GAD who were randomized to nine weeks of treatment with the treatment program and weekly support, or a waiting-list control group. Statistically significant moderate to large effects were observed on primary and secondary outcomes in favour of the treatment. The exception was a measure of quality of life, with no significant difference between the two groups. The treatment effects were maintained at a six-months follow-up. Study III was a pilot trial including 33 participants diagnosed with GAD. A within-group design was used to investigate the effects of the treatment program delivered with automated messages and support on demand. Significant and large within-group effects were observed on all outcome measures at 
post-treatment with the exception of quality of life, for which there was a small effect. Study IV was a pilot factorial design trial that compared the acceptance-based treatment program against a selftailored treatment, as well as two types of support: scheduled support and support on demand. The study included 85 participants with GAD randomized to four different treatment groups. Significant moderate to large effects were observed in all treatment groups, with no statistically significant differences between the groups on self-rated outcome measures. Receiving scheduled support was rated as more positive than support on demand, and self-tailored treatment was rated as more positive than the acceptance-based treatment. Treatment satisfaction was high in all studies.

In conclusion, the studies indicate that an internet-based treatment based on acceptance, mindfulness, and valued action is a viable option in the treatment of GAD.

Keywords: acceptance, generalized anxiety disorder, internetbased treatment, anxiety, cognitive behaviour therapy 


\section{Empirical studies}

I. Dahlin, M., Ryberg, M., Vernmark, K., Annas, N., Carlbring, P., \& Andersson, G. (2016). Internet-delivered acceptance-based behavior therapy for generalized anxiety disorder: a pilot study. Internet Interventions, 6, 16-21.

II. Dahlin, M., Andersson, G., Magnusson, K., Johansson, T., Sjögren, J., Håkansson, A., Magnusson, M., Kadowaki, A., Cuijpers, P., \& Carlbring, P. (2016). Internet-delivered acceptance-based behaviour therapy for generalized anxiety disorder: a randomized controlled trial. Behaviour Research and Therapy, 77, 86-95.

III. Dahlin, M., Carlbring, P., Håkansson, A., \& Andersson, G. (In press]. Internet-based self-help using automatic messages and support on demand for generalized anxiety disorder: an open pilot study. Digital Psychiatry.

IV. Dahlin, M., Johansson, A., Romare, H., Carlbring, P., \& Andersson, G. Worry-specific versus self-tailored internet-based treatments for generalized anxiety disorder, with scheduled support or support on demand: a pilot factorial design trial. Unpublished manuscript. 


\section{Abbreviations}

AAQ-II

ANOVA

ACT

ABBT

BAI

BBQ

BDI-II

CBT

DSM

Face-to-face

GAD

GAD-7

GAD-Q-IV

GSE

ICBT

ICD

MDD

MINI

PHQ-9

PSWQ

SCID

QOLI
Acceptance and Action Questionnaire II

Analysis of variance

Acceptance and Commitment Therapy

Acceptance-Based Behaviour Therapy

Beck Anxiety Inventory

Brunnsviken Brief Quality of Life

Inventory

Beck Depression Inventory II

Cognitive Behaviour Therapy

Diagnostic and Statistical Manual of Mental

Disorders

Traditional therapy with a therapist and client who meet in person

Generalized Anxiety Disorder

Generalized Anxiety Disorder 7-item scale

Generalized Anxiety Disorder

Questionnaire-IV

General Self-Efficacy Scale

Internet-based Cognitive Behaviour

Therapy

International Classification of Diseases

Major Depressive Disorder

Mini International Neuropsychiatric

Interview

Patient Health Questionaire-9

Penn State Worry Questionnaire

Structured Clinical Interview for DSM

Quality of Life Inventory 


\section{Table of contents}

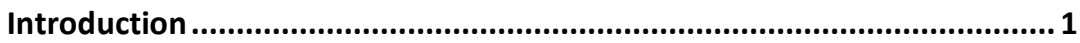

Generalized anxiety disorder ............................................................ 3

Clinical presentation ................................................................. 3

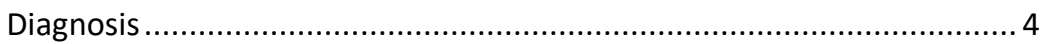

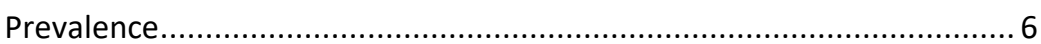

Risk factors and natural course ......................................................... 7

Biological, cognitive, and social aspects of GAD .................................. 8

Comorbidity................................................................................ 10

Individual suffering and costs for society ..................................... 11

Cognitive behaviour therapy................................................................... 12

Different treatment models ............................................................ 13

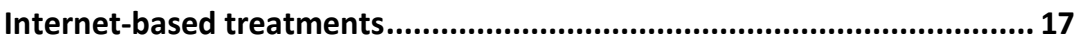

Internet-based treatments for GAD ................................................ 19

Treatment programs ..................................................................... 19

Change during treatment ............................................................ 22

The effects of support ............................................................ 23

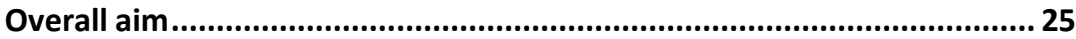

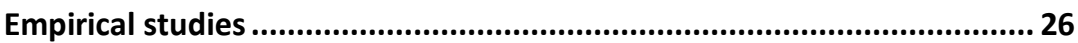

Material and methods .................................................................. 28

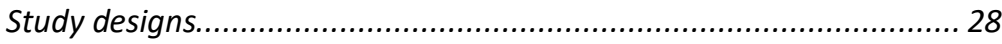

Eligibility criteria and measures .................................................. 30

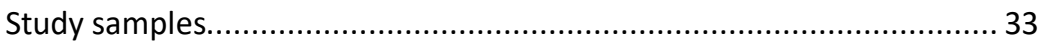

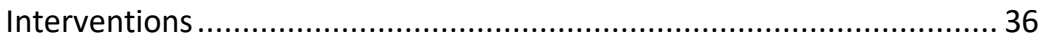




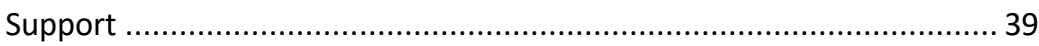

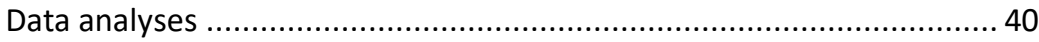

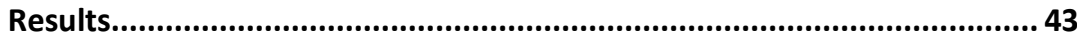

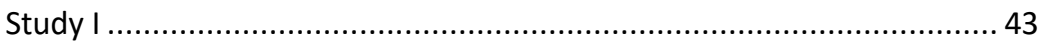

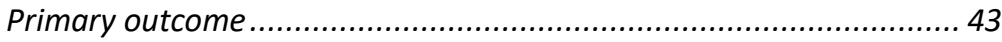

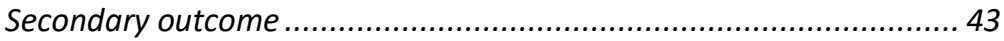

Treatment evaluation ................................................................... 43

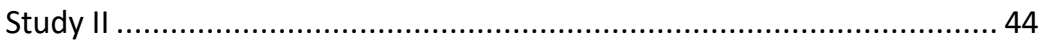

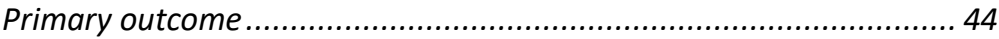

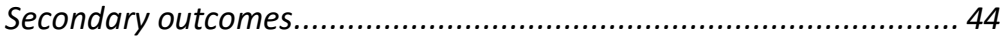

Treatment evaluation ................................................................. 45

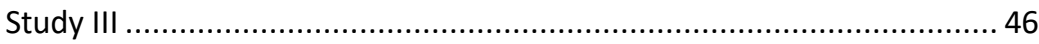

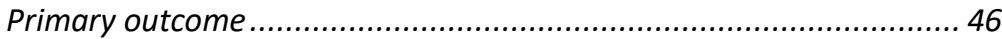

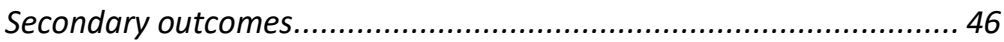

Treatment evaluation ............................................................. 46

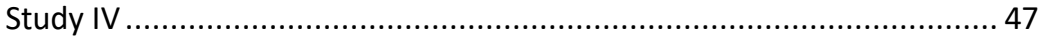

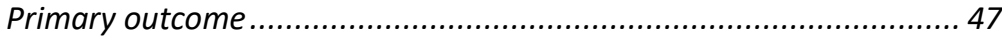

Secondary outcomes............................................................. 48

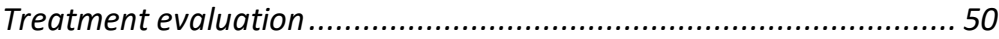

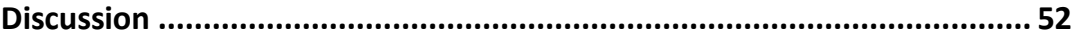

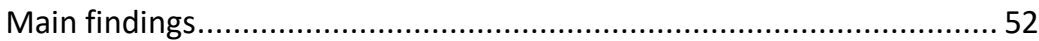

Outcome measures and diagnosis............................................. 52

Effects of different types of support ............................................. 56

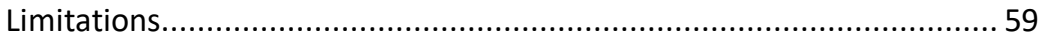

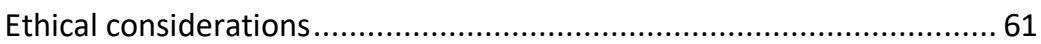

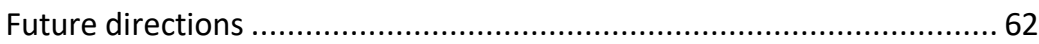

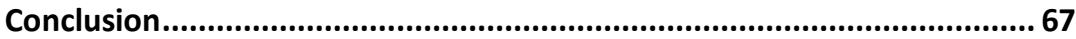

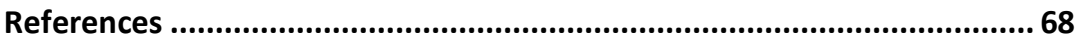




\section{Introduction}

Worrying is a natural part of being human. We all encounter periods or situations when we worry about something that might happen or what we might need to do. For many of us this is a temporary process that ends after the problem at hand has been solved, but for some the worry does not go away it merely shifts to other areas of concern. When worry takes over and negatively affects a person's functioning and well-being, he or she may suffer from generalized anxiety disorder (GAD). GAD is a disabling and chronic condition associated with elevated risks of developing other anxiety or mood disorders, substance abuse, and somatic conditions, such as chronic pain and cardiovascular disease. The disorder is one of the most common psychiatric disorders in primary- and ambulatory care.

Cognitive behaviour therapy (CBT) is the recommended psychological treatment for GAD, using techniques such as cognitive restructuring, exposure and relaxation. In recent years, components such as acceptance, mindfulness, and values-work have been incorporated in CBT via acceptance and commitment therapy (ACT), and other treatment models in the "third wave" of CBT. These treatments have in common that they shift the therapeutic focus away from eliminating symptoms, and instead teach the patient to develop an accepting stance towards thoughts and feelings. Another important principle is to help the patient engage in behaviours that are consistent with what they think is important in life, instead of getting caught in a struggle to eliminate symptoms. Another development that has influenced psychological treatments in recent years is the use of internet as a delivery format. Research on internet-based treatments has been extensive in the past two decades and is today considered an evidencebased treatment for a number of disorders and conditions. However, there is still much to explore and understand regarding the effects of 
different treatment models and what impact different ways of delivery and support has on treatment outcome.

This thesis is the result of two paths I have taken as a licensed clinical psychologist. As a clinician, I am an advocate of the scientistpractitioner perspective. I believe that the scientific and clinical worlds can and should be integrated in our efforts to develop treatments. Fortunately, I have had the opportunity to continue to do research after graduation in collaboration with Gerhard Andersson, Per Carlbring, and others. Without all these years of continued research, this thesis would never have been possible. The other path, which has developed during my years of engaging in clinical work, is to keep treatments as simple and straight forward as possible. A challenging and important question in clinical practice is: How do we teach what is necessary and help clients in a way that is comprehensible, easily transformed to behavioural change, and at the same time effective? I believe that internet-based treatment is one way to accomplish this. The programs help both the clinician and the patient to focus on the work that needs to be done, and guide them through methods that have been shown to be effective, in a straight forward manner.

This thesis aims to examine the effects from a novel internet-based treatment program for GAD, based on acceptance, mindfulness, and valued action, and how well this treatment works with different types of support. My hope is that the thesis will shed some light on how GAD can be treated with modern and updated forms of internet-based treatments and CBT. 


\section{Generalized anxiety disorder}

\section{Clinical presentation}

GAD is characterized by excessive and uncontrollable worry accompanied by several somatic symptoms (American Psychiatric Association, 2013). The worry is focused on everyday events in the near or distant future that are perceived as dangerous or troubling. It can be described as a constant threat monitoring and activation of cognitive problem-solving aimed at potential threats (Heimberg, Turk, $\&$ Mennin, 2004). This threat monitoring affects all aspects of life, and can sometimes even be difficult for therapists to handle in therapy. During my years as a clinical psychologist and supervisor I have realized on many occasions how rewarding and challenging it can be to treat a person with GAD. The reward of helping someone get out of their head and instead appreciate the present moment is great. At the same time therapist can find it difficult to deliver treatment in an effective way. Worry, independence and reassurance seeking are reported to influence therapy in negative ways and can make it hard to focus on what needs to be done during sessions (Szkodny, Newman, \& Goldfried, 2014). Another common obstacle is disbelief in the ability to treat GAD patients with an evidence-based protocol due to comorbidity and lack of adherence. A typical clinical presentation of someone suffering from GAD is presented below.

Linda has had reoccurring consultations in primary care regarding headaches, sleeping problems and stomach complaints, with no objective findings of underlying medical conditions. She reports often being stressed and at some occasions has even had panic attacks. She has a hard time relaxing and says it feels like she is letting her guard down. A few years back she was depressed after a particularly 
stressful period in life. She just could not cope anymore and shut down completely. After a period of sick leave and with the help of medication she got better. Linda describes herself as a born worrier. She worries constantly, mostly about work, family and friends. She says it feels like her mind is determined to focus on what might go wrong. Even small things can trigger uncertainty and "what if" scenarios that scares her. Anxiety is never far away and she often feels overwhelmed and cries. She tries to handle the worry by asking her husband for advice and reassurance that things will be fine. His calm and helping manner make her feel better. But even though he answers her questions and tells her everything will be ok, the worry seems to return after a while anyway. She likes to keep track of the family so she can be on top of things, and gets angry if someone "disappears" without telling her. Linda's friends and family often tell her that she needs to stop worrying so much. She would love to let the guard down and be able to relax, but do not think it is possible or even really desirable. She says she could not live with herself if something went wrong and she could have prevented it. Sometimes she thinks that her husband and friends are irresponsible in the way they act and think. Lately, the worry has gotten worse. Her son has a hard time in school and she does not know what to do. Her son never leaves her mind, making it hard to focus on anything else. She has a hard time falling asleep and often wakes up in the middle of the night. It feels like her head is about to explode and panic is just around the corner. Linda has started therapy, and the psychologist tell her she can break free from worry. She hopes he is right.

\section{Diagnosis}

Historically, diagnostic criteria for GAD have been criticized for lacking specificity, primarily because worry is present in many other anxiety and depressive disorders (Crocq, 2017). Some researchers have even argued that GAD is the most basic anxiety disorder, with other 
disorders best described as extensions of GAD (Barlow, 2002). Since the introduction of the disorder in the third version of the Diagnostic and Statistical Manual of Mental Disorders (DSM-III) (American Psychiatric Association, 1980) defining the disorder as the presence of persistent anxiety for one month, it has been revised considerably with improved reliability. In the fifth, and current, version of the Diagnostic and Statistical Manual of Mental Disorders (DSM-5) (American Psychiatric Association, 2013), GAD is characterized by:

- Excessive anxiety and worry (apprehensive expectation) occurring more days than not for at least six months, about a number of events or activities.

- The individual must find it difficult to control the worry.

- The worry and anxiety must be associated with at least three of the following symptoms:

$\circ$ Restlessness or feeling keyed-up or on edge

$\circ$ Being easily fatigued

o Difficulty concentrating or mind going blank

o Irritability

○ Muscle tension

o Sleep disturbance

- The worry or symptoms must cause clinically significant distress or impairment.

- The symptoms should not be better explained by other mental disorders, medical conditions, or effects from substance abuse.

As seen in the DSM-5 criteria, the main component is an excessive worry that is present more days than not, and is difficult to control. The most common worry topics seen in persons with GAD are not different from what we all worry about (work, health, family), but are more frequent and intense compared with the worry observed in non-clinical populations (Dugas, Freeston, et al., 1998; Olatunji, Wolitzky-Taylor, Sawchuk, \& Ciesielski, 2010). A study by LaFreniere and Newman 
(2020) investigating the nature of worry in GAD showed that the average number of unique worries during a ten-days period was 34.3 for GAD patients. Furthermore, on average, $89.60 \%$ of the worries did not come true during a 30-day period. A study comparing time spent on worry in a GAD sample and a non-clinical sample showed that on average the non-clinical sample spent 55 minutes worrying per day, and the GAD sample 310 minutes (Dupuy, Beaudoin, Rheaume, Ladouceur, \& Dugas, 2001). This provides some indications about the magnitude of worry seen in GAD compared to the worry we all have from time to time. The worry is differentiated from other anxiety disorders through the criterion that the worry concerns several everyday events or activities. In other anxiety disorders, the worry is concentrated on a more specific area of concern, e.g., fear about bodily symptoms in panic disorders or negative evaluations in social phobias (Hirsch, Mathews, Lequertier, Perman, \& Hayes, 2013).

\section{Prevalence}

Epidemiological studies from Europe and the U.S. indicate that the lifetime prevalence of GAD is between 3 to $6 \%$, and the 12-month prevalence is between 1 to $4 \%$ in the general population (Kessler, Petukhova, Sampson, Zaslavsky, \& Wittchen, 2012; Revicki et al., 2012; Wittchen, 2002). The disorder is approximately twice as common among women. If the criterion of a six-month period of worry is reduced to one month, lifetime prevalence rises to $9.1 \%$ (Ruscio et al., 2007). If the excessive anxiety and worry criteria are loosened and added to the one-month criterion, life time prevalence rises to $12.8 \%$. This indicates the magnitude of possible sub-clinical GAD present in the general population. Sub-clinical GAD has negative impact on functioning and well-being, and are associated with heightened risk of developing anxiety and depressive disorders, besides the risk of developing GAD (Haller, Cramer, Lauche, Gass, \& Dobos, 2014). Furthermore, GAD is a common disorder in ambulatory medical care, 
with prevalence rates ranging between 8 to $10 \%$ (Revicki et al., 2012), as well as in specialist mental health care, with a prevalence of $13 \%$ (Bobes, Caballero, Vilardaga, \& Rejas, 2011). Research also indicates that GAD may be the most common anxiety disorder in primary care (Kertz \& Woodruff-Borden, 2011). Swedish research shows similar results. A study examining the point prevalence of GAD in Sweden's general population found a prevalence of $8.8 \%$ when using a standard cut of value on the screening measure used, and $4.7 \%$ when using a stricter cut of value (Johansson, Carlbring, Heedman, Paxling, \& Andersson, 2013). In Swedish primary care patients, the lifetime prevalence has been estimated to range from 4.1 to $6.0 \%$ for men and 3.7 to $7.1 \%$ for women (Munk-Jørgensen et al., 2006).

\section{Risk factors and natural course}

Studies show that approximately $30 \%$ of the risk of developing GAD can be attributed to genetic factors (Gottschalk \& Domschke, 2017; Mackintosh, Gatz, Wetherell, \& Pedersen, 2006). These genetic vulnerabilities are to a large extent similar to those of other anxiety disorders, as well as depression (Cerda, Sagdeo, Johnson, \& Galea, 2010) The genetic factors seen in GAD are also, to a large extent, the same as those seen in the personality trait neuroticism, which is characterized by emotional reactivity, insecurity, anxiety, and vulnerability to stress (Hettema, Neale, Myers, Prescott, \& Kendler, 2006). These findings suggest that environmental and psychological factors play a major role in the vulnerability's trajectory. Known environmental risk factors are parents with previous or current psychiatric conditions, overprotective or cold caregivers, and maltreatment (Beesdo, Pine, Lieb, \& Wittchen, 2010; Moreno-Peral et al., 2014). Furthermore, stressful life events during childhood and/or in

the last month, being 30-64 years old, being separated/divorced/widowed, receiving psychiatric care, and having low economic resources are other factors that may trigger GAD. 
Psychological risk factors include internalizing and externalizing disorders in childhood or adolescence, personality traits of neuroticism, behavioural inhibition, harm avoidance and reward dependency, the presence of other psychiatric and personality disorders, and negative coping skills such as self-blaming, catastrophizing, reassurance seeking, or cognitive avoidance (Cougle et al., 2012; Legerstee, Garnefski, Verhulst, \& Utens, 2011; MorenoPeral et al., 2014; Nasiri, Mashhadi, Bigdeli, \& Chamanabad, 2020). Taken together, this indicates that being born with a vulnerability to neuroticism and anxiety enhanced by past or current negative environmental factors handled with negative coping skills leads to a high risk of developing GAD.

The onset of GAD can occur at all life stages, but compared with other anxiety disorders, it has a later onset, with a median onset age of 30 years (Kessler et al., 2012). There is a sharp increase in cases in adolescence, after which, the number of new cases evens out to a steady flow until old age. The disorder is considered chronic if not treated, with periods of more intense worry and anxiety that subsides to less intense periods until stressful circumstances trigger new periods of worry and anxiety (Yonkers, Bruce, Dyck, \& Keller, 2003). Sometimes these periods last years but are sometimes shorter. Spontaneous recovery can occur, but a large proportion of cases experience relapse within a few years. At the same time, many who suffer from GAD do not seek treatment for worry and typically have had symptoms of the disorder for 5 to 11 years before GAD is diagnosed (Hoffman, Dukes, \& Wittchen, 2008).

\section{Biological, cognitive, and social aspects of GAD}

GAD is associated with several negative biological, cognitive and social aspects. Studies show that individuals suffering from GAD more often, and for longer periods of time are in a bodily state of 
dysregulation compared with healthy controls (Allgulander, 2012; Patriquin \& Mathew, 2017). A hypervigilant state, with higher restingstate hearth rate, lower hearth rate variability, and elevated skin conductance compared with health controls has been observed. This heightened activation is even present during sleep. It has been hypothesized that the hyperactivation is an effect from strong reactions to threatening or ambivalent information in the amygdala, and the constant cognitive activation (worry) seen in GAD (Hilbert, Lueken, \& Beesdo-Baum, 2014).

Suffering from GAD is associated with lower levels of attentional control, and cognitive bias in attention to threat compared with nonclinical populations (Goodwin, Yiend, \& Hirsch, 2017). Furthermore, this bias is of a more general character compared with other anxiety disorders (Hirsch et al., 2013). The bias is also present in the cognitive processing of information, resulting in negative interpretations of ambivalent information and a heightened tendency to expect negative outcomes (Hirsch \& Mathews, 2012). People with GAD also report elevated levels of intrusive thoughts, difficulty concentrating, and less confidence in their own cognitive abilities and memory compared with healthy controls and many other anxiety disorders (Hirsch et al., 2013; Olatunji et al., 2010).

People with GAD rate their worry as more negative than healthy controls and those with other anxiety disorders, fearing negative effects from worrying and a stronger need to exert control over the worry (Hirsch et al., 2013). Although these negative views are present, persons with GAD often also report positive believes of worry (Heimberg et al., 2004). Individuals with GAD tend to believe that worrying can help them avoid negative outcomes, enhance motivation, cope with fears, and is a positive personality trait to a higher degree than healthy controls (Borkovec \& Roemer, 1995; Ladouceur, Blais, Freeston, \& Dugas, 1998) 
GAD is also associated with negative social effects. People with GAD tend to view other people as more hostile, controlling, and aggressive (Newman, Llera, Erickson, Przeworski, \& Castonguay, 2013). At the same time, persons with GAD can be viewed as intrusive, avoidant, and more easy to manipulate by others. Research has shown that people with GAD are at an increased risk of experiencing negative events, such as parental rejection, assault, and abusive partners (Przeworski et al., 2011). Furthermore, research also indicates that individuals with GAD have a higher risk of being divorced, lacking close relationships, and having more problematic family relationships compared with individuals who have other anxiety disorders (Newman et al., 2013). Presence of these negative social factors are associated with elevated symptoms and worse prognoses for GAD (Newman, Cho, \& Kim, 2016).

\section{Comorbidity}

The rate of comorbid disorders in persons with GAD is high. Studies have shown that up to as many as approximately $90 \%$ of GAD patients have at least one comorbid psychiatric disorder at some point (Grant et al., 2005; Revicki et al., 2012). Suffering from GAD increase the risk of developing other anxiety disorders as well as mood disorders and substance abuse disorders (Ruscio et al., 2007). The most common comorbid disorders are depressive disorders, social phobias, panic disorders and alcohol or substance abuse disorders (Newman et al., 2016). Common comorbid personality disorders include obsessive compulsive personality disorder and avoidant personality disorder. The disorder is associated with increased mortality (Meier et al., 2016), as well as increase in suicidal ideation and behaviour compared with the normal population, even without comorbid depression. GAD is also associated with high rates of comorbid somatic disorders and symptoms, such as pain, peptic ulcer disease, diabetes, irritable bowel syndrome (IBS), and cardiac symptoms (Beesdo et al., 2009; Hoffman 
et al., 2008). For example, in a study by Martens et al. (2010) the risk for cardiovascular disease was $62 \%$ higher when suffering from GAD, even when controlling for comorbid depression, medication and demographic factors. The co-occurrence of other psychiatric or somatic disorders leads to increased functional impairments with elevated levels of personal suffering as well as higher costs for society (Hoffman et al., 2008; Revicki et al., 2012).

\section{Individual suffering and costs for society}

GAD is associated with decreased psychosocial and role functioning, work productivity, emotional and physical well-being, and quality of life (Hoffman et al., 2008; Revicki et al., 2012). The reduction in health-related quality of life is comparable with suffering from major depressive disorder (MDD) or chronic medical conditions, when suffering from "pure" GAD. When a comorbid psychiatric or somatic disorder is present, the reduction in functioning and life quality is even greater (Grant et al., 2005). The economic burden associated with GAD is also high. In a study by Marciniak et al. (2005) the total lifetime medical cost for individuals suffering from any anxiety disorder was $\$ 6475$, and a GAD diagnosis added $\$ 2138$ to that total. Apart from medical costs, suffering from GAD is associated with elevated days on sick leave from work (Hoffman et al., 2008). When controlling for socioeconomic factors and comorbid disorders, those with GAD, on average, take 1.5 to 5.4 days on sick leave over a 30-day period, which is in the same range as for MDD and several chronic medical conditions. Individuals suffering from GAD also seek more medical treatments (Revicki et al., 2012), often over diffuse medical symptoms, and visit primary care, emergency care, gastroenterology and cardiology clinics significantly more often than those without GAD. When considering this elevated use of medical care and the high number of days on sick leave, GAD costs are estimated to be higher than for any other anxiety disorder. 


\section{Cognitive behaviour therapy}

GAD can be treated with medication or psychological treatments. The recommended first line medication is selective serotonin reuptake inhibitor (SSRI) which is effective for reducing GAD symptoms and more tolerable than other types of medications for anxiety symptoms (Carl, Witcraft, et al., 2020; Tyrer \& Baldwin, 2006). Even with a growing number of psychological treatment studies on GAD based on different theoretical orientations, the recommended psychological treatment for GAD is cognitive behaviour therapy (CBT). CBT is a goal directed treatment approach that teach the patient active strategies to manage cognitive, emotional and behavioural aspects of suffering. Historically, the effects of CBT on GAD have been smaller than for some other anxiety disorders, but recent meta-analyses including both face-to-face and internet-based treatments have shown larger effects. A meta-analysis by Cuijpers et al. (2014) including 41 randomized controlled trials (RCTs) showed moderate to large, pooled betweengroups effect sizes for psychotherapy versus control conditions (waitlist, placebo or treatment as usual) on GAD symptoms $(g=0.84)$ and comorbid depressive symptoms $(g=0.71)$. An updated metaanalysis by Carl et al. (2020) included 79 RCTs and showed similar results, with moderate to large effects from CBT compared with control conditions (waitlist, placebo or treatment as usual) on GAD outcomes $(g=0.76)$ and depression outcomes $(g=0.64)$. Another recent meta-analysis by Carpenter et al. (2018) examined the effects from CBT versus a placebo (psychological or pill) in anxiety disorders, including GAD. CBT for GAD showed a large effect size $(g=1.01)$ compared with the placebo, and together with CBT for OCD had the largest effects of all included diagnoses.

Studies indicate that individuals with severe GAD symptoms, or comorbid disorders, experience a more rapid change during treatment (Cuijpers et al., 2014; Newman, Przeworski, Fisher, \& Borkovec, 
2010). Furthermore, treatment effects are maintained at two-year follow-ups, with the exception of the positive effects on comorbid depression. Approximately $50 \%$ of patients reach high end-state functioning after treatment, and the numbers needed to treat is 2.23 , indicating that during treatment, approximately every second patient is not going to respond to the treatment (Cuijpers et al., 2014). Gersh et al. (2017) investigated dropout rates in individual psychotherapy for GAD in a meta-analysis that included 45 RCTs. The results showed that the mean dropout rate was approximately $17 \%$, which is similar to dropout rates in the treatment of other conditions. Analyses did not reveal any moderator effects of treatment type, nor did they find any significant effects on dropout in relation to mean age, gender, comorbidity, symptom severity, study quality, numbers of sessions, or experience of the therapist. Different attempts to enhance the effects of CBT have been made. Studies by Borkovec and colleagues indicate that adding more sessions in face-to-face treatment do not lead to significantly larger effects (Borkovec \& Costello, 1993; Borkovec, Newman, Pincus, \& Lytle, 2002). However, adding supportive technology, such as a software with exercises and registrations, has been shown to enhance the effects of group therapy for GAD (Newman, Przeworski, Consoli, \& Taylor, 2014).

\section{Different treatment models}

Several CBT protocols for GAD have been developed with the aim to enhance treatment effects. Even if the treatments are similar in some ways, the conceptualization of worry in each of these models has some distinct features (Behar, DiMarco, Hekler, Mohlman, \& Staples, 2009). The well-established models include: the avoidance model (Borkovec, Alcaine, \& Behar, 2004); the metacognitive therapy (MCT) model of GAD (Wells, 1995); the intolerance of uncertainty model (IUM) (Dugas, Gagnon, Ladouceur, \& Freeston, 1998); and the acceptancebased behavioural therapy (ABBT) model for GAD (Roemer \& 
Orsillo, 2002). A more recent model is the contrast avoidance model (Newman \& Llera, 2011). Several of the models include similar treatment techniques even if the conceptualizations differ. The most frequently used techniques are cognitive restructuring, relaxation, exposure in vivo or imaginal, and problem solving.

Borkovec was one of the pioneers in the development of treatments for GAD and his research has been highly influential in the understanding of the disorder and how to treat it. Borkovec's avoidance model (Borkovec et al., 2004) is based on Mower's two-factor fear theory (Mowrer, 1951), as well as the emotional processing model developed by Foa and Kozak (1986). According to the avoidance model, worry is a cognitive activity that aims to avoid negative mental images and the reactions (emotional and physical) that are associated with them. The avoidance is negatively reinforced as a consequence of the distancing from the troubling images, as well as through experiencing the idea that the worry helped the person avoid the feared outcome. The drawback of this avoidance is that it inhibits the emotional processing of what is feared and makes habituation and extinction impossible. As a consequence of this theoretical assumption, treatment is aimed towards breaking avoidance through relaxation techniques, stimulus control and cognitive therapy, and enabling the processing of feared stimuli trough exposure. The treatment developed by Borkovec and colleagues has been considered the gold standard of psychological GAD treatments since its development several decades ago.

One of the recent developments in CBT is the so called third wave of cognitive behaviour therapies (Hayes \& Hofmann, 2017). Treatments generally considered being a part of this development are treatments that target a person's relationship to symptoms and thoughts, rather than the symptoms per se and the specific cognitive content. Another commonality of these treatments is the incorporation of acceptance, mindfulness, and values as important treatment components, with Acceptance and Commitment Therapy (ACT) (Hayes, Strosahl, \& 
Wilson, 1999) being one of the central treatment models. With the help of these strategies' acceptance-based treatments aim to help patients develop an accepting stance towards symptoms and engage in a meaningful life rather than getting stuck trying to eliminate symptoms and feelings that are a part of life. A recent meta-analysis indicated that $\mathrm{ACT}$ is more effective than waitlist control conditions and equally effective as CBT for anxiety and depressive symptoms (A-Tjak et al., 2015). In an recent RCT an ACT protocol targeting repetitive negative thinking was tested with 48 participants with GAD and/or depression being randomized to treatment or wait list control condition (Ruiz et al., 2020). The two-session protocol lead to significant and large effects on primary and secondary outcomes compared with the control condition, and the effects were maintained at three months follow-up.

Acceptance-based behaviour therapy (ABBT) is a treatment model incorporating recent developments of acceptance, mindfulness and values into a treatment specifically designed for GAD. ABBT's underlying theoretical model is based on the concept cognitive fusion and the experiential avoidance theory (Roemer \& Orsillo, 2002) which is central in ACT. Cognitive fusion refers to the tendency believe in, and rely on thoughts to the extent that they become more important than what actually happens (Hayes et al., 1999). Experiential avoidance is the unwillingness to experience negative internal experiences (thoughts, feelings, images, bodily sensations), leading to avoidance or rigid control strategies to minimize the risk of having these experiences and to handle them if they arise. Efforts to control unpleasant experiences do not stop them from arising and lead to a negative cycle of more symptoms and control strategies. As a consequence, life is restricted to trying to handle these cycles instead of living a life filled with meaningful activities. According to ABBT, the worrying seen in GAD is a response in the service of experiential avoidance that is negatively reinforced. The treatment developed from this model is based on three aspects: the development of a mindful stance to internal experiences, acceptance of internal experiences, and 
the engagement in valued actions (Hayes-Skelton, Orsillo, \& Roemer, 2013). It is hypothesized that together, these three aspects will help a person suffering from GAD break the negative cycle of cognitive fusion and experiential avoidance and get engaged in their lives, instead of having an internal focus on thoughts, feelings, and sensations and handling these with worry. In ABBT, thoughts and worry are viewed as a process that you can choose to engage in or not (through mindfulness and acceptance strategies). Contrary to the cognitive therapy in Borkovec's model, it is the process of choosing to avoid or control thoughts and feelings that is central to therapy and not identifying and challenging the thoughts in themselves. Several ABBT trials for GAD have been published, providing support for the treatment approach when delivered face-to-face (Hayes-Skelton, Roemer, \& Orsillo, 2013; Roemer \& Orsillo, 2007; Roemer, Orsillo, \& Salters-Pedneault, 2008).

When comparing different face-to-face treatments for GAD with one another, no clear or repeated results suggest that one model is more effective than the other. Several treatments have been compared with applied relaxation (AR) as a stand-alone treatment, showing no significant differences at post-treatment (Arntz, 2003; Borkovec \& Costello, 1993; Dugas et al., 2010; Hayes-Skelton, Roemer, et al., 2013; Ost \& Breitholtz, 2000), even if there are some indications that CBT might be more effective than AR at follow-up (Cuijpers et al., 2014). A meta-analysis by Montero-Marin et al. (2018) indicated that this is not unique for GAD, but also might be the case for panic disorder, social phobias and specific phobias. Few studies have compared different CBT models. Borkovec's treatment model has been compared with metacognitive therapy (MCT) with preliminary results in favour of MCT (Nordahl et al., 2018). In a study by Avdric, Morrissey, and Boshen (2014) 51 participants with GAD were randomized to six weeks of ACT group treatment or CBT group treatment. Significant effects were seen in both groups on all outcome measures with no differences between the groups. The ACT group 
made a steeper change in worry during treatment but the differences in change was levelled out at follow-up. A recent study randomized 75 participants into Borkovec's treatment, rational-emotive therapy or ACT/ABBT (Stefan, Cristea, Szentagotai Tatar, \& David, 2019). The treatments included 20 sessions, delivered twice a week during the first eight weeks then once a week. All three treatments showed significant and large effects from pre- to post- measure (PSWQ: Borkovec $d=$ 0.88, REBT $d=1.15, \mathrm{ACT} / \mathrm{ABBT} d=1.01$ ), with high response rates in all groups (Borkovec, 69.6\%; REBT, 70.8\%; ACT/ABBT, 79.2\%). No significant between-groups differences were observed regarding effect sizes, response rates, or drop out.

\section{Internet-based treatments}

Internet-based treatment is originally a development of bibliotherapy with self-help books made possible by the introduction of home computers in the 1980's and the internet in the mid 1990's (Andersson, 2018). With these two technical revolutions becoming a part of everyday life self-help books could be converted to this media. By converting books to files on a computer they could easily be distributed online and could also be developed and changed over time in ways traditional books cold not. Most internet-based treatments today are based on CBT since the structured format, and techniques used in face-to-face CBT was easy to convert to the format. Internetbased cognitive behaviour therapy (ICBT) can be described as a treatment package with several chapters, or modules accessed online (Andersson, 2015). The modules address different aspects of a disorder or problem and include psychoeducation, exercises and homework that the patient is expected to work with during a period of time (usually one module week). Some treatments are purely self-help, but treatments often include some type of support from a therapist that guide the patient trough the treatment. The contact can be trough a secure message system or telephone. The support can vary in intensity 
and structure, but the most common types of support is weekly scheduled support or support on demand. In weekly support the participant is usually instructed to send a report at the end of the week to the therapist who provides feedback and encouragements. If the participant fails to send a report the therapist contacts the participant. In support on demand the participant work with the program independently and contact the support if guidance is needed. The therapist replies to questions but do not contact the participant unless the participant asks for help. Some of the benefits with the treatment format is that it makes treatment more accessible, scalable and cost effective compared with face-to-face treatment (Andersson \& Titov, 2014). Furthermore, the treatments are often tested in RCTs making it possible to deliver evidence-based treatments in a structured way.

The research and development of ICBT have been extensive in the last decades. Today, the format is considered an effective way to deliver treatments for several psychiatric conditions, such as different types of anxiety and depression (Andrews et al., 2018). Treatment effects are often comparable to face-to-face treatments (Carlbring, Andersson, Cuijpers, Riper, \& Hedman-Lagerlof, 2018) and are maintained at long-term follow-up (Andersson, Rozental, Shafran, \& Carlbring, 2018). As a result of the extensive research internet-based treatments are included in the treatment guidelines for depression and anxiety disorders issued by authorities in many countries. In a recent metaanalysis by Andrews et al. (2018) including 64 RCTs on depression and anxiety disorders the mean effect size compared to control conditions (waitlist or treatment as usual) was $g=0.80$. The effects were maintained at 3 to 36 months follow-up. Median adherence was $66 \%$ and $86 \%$ was satisfied with treatment. On average, the therapists in face-to-face treatments spent 7.8 times the time used in ICBT, but no significant differences in effects between the two formats was found. Research on somatic conditions such as chronic pain, tinnitus, Irritated bowel syndrome has also generated positive results (Andersson, 2018). 


\section{Internet-based treatments for GAD}

The research on internet-based treatments for GAD has been considerable in the past few years, with more than 10 different treatments programs evaluated in clinical trials including individuals with GAD (Titov, Andersson, \& Paxling, 2016). A meta-analysis, that included 11 RCTs by Richards et al. (2015) on internet-based treatment for GAD showed significant and large effects on GAD symptoms $(d=0.91)$ and worry $(d=0.71)$ compared with waiting-list controls. Medium to large effects were found for comorbid anxiety $(d$ $=0.57)$, depression $(d=0.63)$, distress $(d=0.91)$, and disability $(d=$ $0.77)$, and a small effect on quality of life $(d=0.38)$. When only CBT programs were included in the analysis, the heterogeneity decreased, and the effect size on GAD symptoms and worry increased $(d=1.19$ and $d=0.87$, respectively). Furthermore, studies have shown that internet-based treatment for GAD can be implemented in routine care with significant and medium to large within-group effects on GAD outcomes (Mewton, Wong, \& Andrews, 2012; Richards et al., 2016; Sunderland, Wong, Hilvert-Bruce, \& Andrews, 2012) and are equally effective across different age groups in adults (Hobbs, Mahoney, \& Andrews, 2017).

\section{Treatment programs}

The treatment programs developed for GAD last, on average, 8 to 12 weeks and include a range of 4 to 12 modules (Titov et al., 2016). The disorder-specific programs usually are based on a generic CBT model of GAD and standard CBT interventions for the disorder (such as psychoeducation, cognitive restructuring, exposure, stimulus control and relaxation), and often include additional treatment components aimed at common co-occurring problems such as depressive symptoms and sleeping problems. The first internet-based treatment for GAD evaluated in a RCT was a disorder specific program developed by Titov et al. (2009) in Australia. The program consisted of six modules 
delivered over 10 weeks. Weekly support via telephone or e-mail and automated messages was included in the treatment. Large effect sizes on GAD measures were found post treatment and support spent 130 minutes on average per participant. I was involved in the development and evaluation of another of the early internet-based treatments for GAD (Paxling et al., 2011). It was a disorder-specific treatment delivered over eight weeks with weekly support. The treatment was, to a large extent, inspired by Borkovec's face-to-face GAD treatment and included eight modules, each with two sections. One section covered applied relaxation, divided into six steps. The other sections included psychoeducation, worry time, cognitive restructuring, problem-solving, worry exposure, interpersonal problem-solving, sleep management, and relapse prevention, in that order. The treatment was evaluated in an RCT with 89 participants randomized into treatment or waiting-list control. Significant and large within- and between-group effects were observed on all outcome measures post-treatment, except quality of life, which showed a medium effect. Follow-up at one and three years after treatment indicated that the effects were maintained or improved. However, only $10.5 \%$ completed the whole treatment, and the mean number of completed modules was $4.8(\mathrm{SD}=2.1)$. Feedback from the participants indicated that the lack of time and extensive material was a hindering aspect. In a second trial, we developed an internet-based psychodynamic treatment (Andersson, Paxling, Roch-Norlund, et al., 2012) based on the self-help book Make the Leap (Silverberg, 2005) which was converted to fit an internet-based treatment structure with weekly assignments in eight modules. In an RCT, 81 participants were randomized to eight weeks of treatment with weekly support with either the CBT treatment, the psychodynamic treatment, or to a waiting list control. The results showed significant moderate to large withingroup effects on all outcome measures for both treatments at post measure and at 18-month follow up. The average number of completed modules in IPDT was $5.9(\mathrm{SD}=2.2)$ and $5.1(\mathrm{SD}=2.5)$ in ICBT. 
Besides disorder-specific treatments, both transdiagnostic (Andersson et al., 2017; Dear et al., 2015; Johnston, Titov, Andrews, Spence, \& Dear, 2011; Titov et al., 2015) and tailored treatments (Carlbring et al., 2011; Nordgren et al., 2014) have been found to be effective in reducing GAD symptoms and other comorbid symptoms. However, the disorder-specific treatments generally lead to a slightly stronger effects on GAD outcomes, compared with the other types of treatments (Titov et al., 2016). This is perhaps not surprising when considering the underlying principles of the different treatment approaches. Transdiagnostic treatments have been developed as a way to address the high levels of comorbidity in patients by targeting general processes of mental health such as avoidance, activation, emotion regulation. The idea of tailored treatments is similar but instead of targeting general principles the treatment modules are selected based on personal preferences and the specific problems presentation of the person going through treatment. It is possible that by targeting general principles or adding components for comorbid conditions some level of specificity in the treatment are lost.

Internet-based treatments studies on ACT (iACT) and acceptancebased treatments is growing rapidly (Thompson, Destree, Albertella, \& Fontenelle, 2020). Studies indicate that the treatment approach is effective in a wide range of problems such as pain (Buhrman et al., 2013), tinnitus (Hesser et al., 2012), sleep problems (Lappalainen, Langrial, Oinas-Kukkonen, Muotka, \& Lappalainen, 2019), and depression (Lappalainen, Langrial, Oinas-Kukkonen, Tolvanen, \& Lappalainen, 2015). A recent meta-analysis by Kelson et al. (2019) including 20 outcome studies on iACT for anxiety indicated that the treatments were effective, with significant effects on anxiety measures and small to large within- and between-group effects compared with control conditions. The average adherence was $80 \%$. However, to my knowledge there are no existing studies on acceptance-based treatments for GAD delivered online except those included in this thesis. A recent study on ABBT as a bibliotherapy for excessive worry 
reported significant effects on GAD related outcomes after 10 weeks of working with the self-help book compared to a waiting list control (Serowik, Roemer, Suvak, Liverant, \& Orsillo, 2020). Few studies have compared iACT with face-to-face treatments. However, a study by Lappalainen et al. (2014) compared iACT with an ACT group treatment for depression, with results indicating that the treatments were equally effective. Further studies comparing iACT with active treatments are needed to investigate the effects of iACT/acceptancebased treatments compared with other forms of ICBT on anxiety.

\section{Change during treatment}

A study by Sunderland et al. (2012) investigated the trajectories of change in an internet-based treatment for GAD and depression. The results showed that generally, a more rapid change in symptoms took place early in treatment, then levelled out, but continued to improve during treatment. Two groups with different patterns were identified: responders and low responders. The responder' trajectories followed the general pattern of an early, stronger effect with continued positive development during treatment. The low responders had a small effect at the start of the treatment, then had no additional positive effects for a period and finally a slight increase in effect at the end of treatment. The low responders were characterized by higher levels of distress, symptom severity, and impairment compared with the responders. The response rates and patterns were equal between the two disorders in the study. In a study investigating how ICBT for GAD is perceived, 36 participants were recruited for an internet-based treatment for GAD and asked to answer questions about helpful and hindering aspects of therapy after each module (Burke, Richards, \& Timulak, 2019). Helpful components that were reported included psychoeducation, supporter interaction, monitoring, relaxation, mindfulness, cognitive restructuring, and reading personal stories. These helpful components led to helpful effects for the participant through the experience of 
support and validation, applying new skills, development of awareness and insight, getting reassurance, and feeling a sense of self-efficacy. Two hindering factors were reported: treatment content/form and technical issues. These factors lead to frustration/irritation, increased anxiety, and a sense of isolation.

\section{The effects of support}

Internet-based treatments often include some degree of contact with a therapist based on research indicating that adding support, in contrast to no support, increase adherence and clinical outcomes (Baumeister, Reichler, Munzinger, \& Lin, 2014; French, Golijani-Moghaddam, \& Schröder, 2017). However, research on the structure of support and its impact on clinical outcomes and adherence are showing inconclusive results. In an RCT by Dear et al. (2015) clinician-guided treatment for GAD was compared with self-help, indicating no significant differences between the two groups on clinical outcomes or treatment satisfaction. Johnston et al. (2011) compared the effects from receiving therapeutic lay person support or support from a therapist and found no differences between the two support types. However, in a study investigating the effects from optional or weekly support, completion rates were $56.6 \%$ for optional support and $82.4 \%$ for weekly support (Hadjistavropoulos, Schneider, et al., 2017). Furthermore, when given the option, $78 \%$ of the participants preferred weekly support over support on demand in a preference trial by Hadjistavropoulos et al. (2019). Those choosing weekly support had higher baseline scores and were 2.7 times more likely to suffer from GAD or panic attacks. Those in the weekly support condition logged in significantly more and sent more messages, with $69 \%$ of those receiving weekly support and $63 \%$ of those receiving optional support completing all modules during treatment. Studies on patient rated alliance in ICBT for GAD indicates that the patients experience alliance as strong, at levels similar to faceto-face treatments, but alliance do not predict treatment outcomes 
(Andersson, Paxling, Wiwe, et al., 2012; Hadjistavropoulos, Pugh, Hesser, \& Andersson, 2017). Furthermore, alliance ratings might be lower when receiving optional support (Hadjistavropoulos et al., 2019).

In summary, several existing treatment models for GAD have been found to be effective as face-to-face treatments. Some of these approaches incorporate newer strategies such as acceptance, mindfulness, and committed action into the treatment. Internet-based treatment for GAD has also been shown to be an effective treatment format. The internet-based treatments for GAD primarily include traditional CBT techniques and an acceptance-based treatment could prove to be a viable alternative to existing treatments. Furthermore, studies indicate that the content and delivery of treatment programs, as well as how support is delivered can be hindering or helpful aspects for treatment. Further studies are needed to better understand how the programs used in internet-based treatments and the use of support functions impact the treatments for GAD. 


\section{Overall aim}

The overall aim of this thesis was to investigate the effects of a novel internet-based treatment for GAD based on acceptance, mindfulness, and valued action strategies. In addition to this another aim was to further investigate how different types of support affect treatment outcomes, adherence and satisfaction with treatment. More specifically the aims were:

- Investigate the effects of a novel internet-based treatment for GAD based on acceptance, mindfulness, and valued action in an initial pilot study (Study I).

- Examine the effects from the treatment program with weekly support compared with a waiting-list control in a controlled study (Study II).

- Examine the effects from the treatment program with support on demand and automated messages in an open pilot study (Study III).

- Examine the effects from the treatment program compared with an active treatment and with two types of support: support on demand and scheduled support in a factorial design pilot trial (Study IV). 


\section{Empirical studies}

This thesis includes four treatment studies that evaluate the acceptance-based treatment program called Oroshjälpen, with different types of support. Table 1 provides an overview of the four included studies. The materials, methods, and participants are presented together, as many of these aspects are similar in all four studies. The results are also be presented together to facilitate a clear overview and comparison of the results in the studies. The results presented are condensed and primarily focus on a selection of outcome measures that represents the effects seen in the studies. 
Table 1. Overview of the four studies in the thesis.

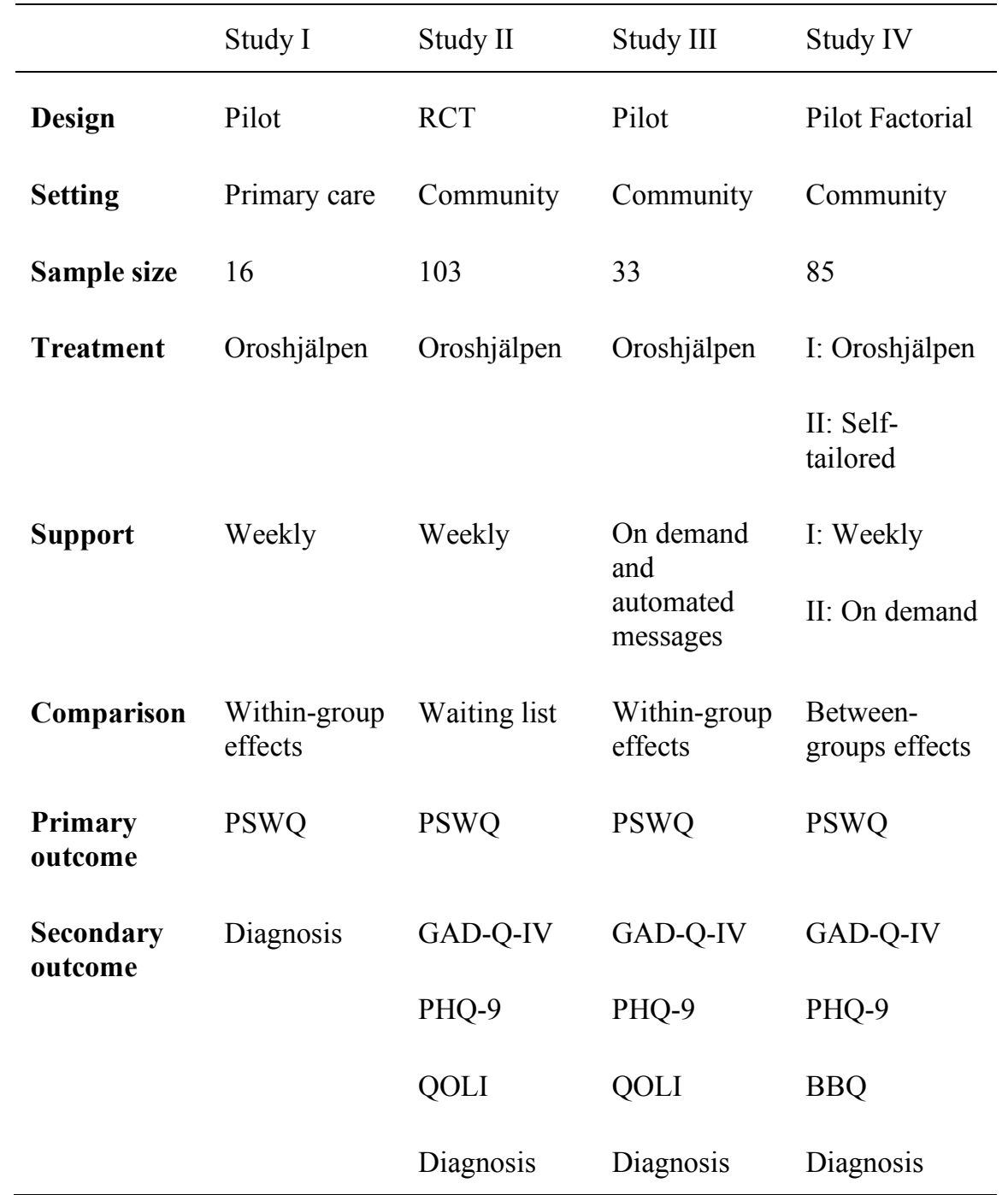

RCT $=$ randomized controlled trial, PSWQ = Penn State Worry Questionnaire, GADQ-IV = Generalized Anxiety Disorder Questionnaire-IV, PHQ-9 = Patient Health Questionnaire-9, QOLI = Quality of Life Inventory, BBQ = Brunnsviken Brief Quality of Life Scale. 


\section{Material and methods}

\section{Study designs}

Study I was a small pilot study that examined within-group effects from the newly developed treatment program with weekly support. Participants were recruited at two primary care clinics in Linköping, Sweden. Consecutive intake and treatment were used, following routines for regular care at the clinics. The general practitioners at the clinics referred patients to the psychologist at the clinic. The psychologist had initial appointments with all referred patients, and if a patient screened positive for a GAD diagnosis, they were asked whether they wanted to participate in a study and receive internetbased treatment. If the participant agreed and gave consent, he/she was given access to the treatment program, instructed to work with one module per week and send a report to the psychologist by the end of each week. In addition, one or two shorter telephone calls, and a live session at the end of treatment were scheduled. Outcome measures were self-reported worry, satisfaction with treatment, and clinical interviews. Measures were collected pre- and post-treatment, and at a follow-up two to three months after treatment.

Study II was a randomized controlled trial (RCT) conducted in a community setting. Participants were recruited through advertising for a treatment study aimed at worry in social media and in a Swedish newspaper. Participants were directed to the study's website, which contained information about the study and how to register. After registration, participants were asked to provide written consent to participate in the study and undergo an online screening. Participants who met the initial screening criteria were contacted for a diagnostic interview conducted by four psychology students under supervision. A final decision to include a participant was made at referral meetings among the four psychology students, a licensed psychiatrist, the principal investigator responsible for the study, and a clinical 
psychologist and psychotherapist (first author on paper II). After the intake was closed, participants were randomized to treatment or a wait list control group. Treatment consisted of Oroshjälpen with weekly support and lasted nine weeks. The primary outcome measure was selfrated worry. Secondary outcomes were GAD and depressive symptoms, and quality of life. Measures were collected pre- and posttreatment, and at a six-month follow-up. A diagnostic interview was made at post-treatment.

Study III was a pilot trial that examined within-group effects of Oroshjälpen as a self-guided intervention with the addition of support on demand and automated messages. Participants were recruited from the control condition in study II after they had answered the post treatment measures. The treatment lasted for nine weeks. As a way to handle the lack of a control condition in the study, data from the previous trial, in which participants were randomized into the waitinglist condition, were included in the analysis. Measures were collected upon inclusion into study II and pre- and post-treatment. With this design, a comparison between nine weeks of waiting for treatment and the subsequent effects from nine weeks of treatment could be performed. The primary outcome was self-rated worry. Secondary outcomes were GAD and depressive symptoms, and quality of life.

Study IV was a factorial pilot trial. Participants were recruited through advertisement in social media and a Swedish newspaper. Participants who registered at the study's website and provided written consent to participate in the study were given access to an online screening. Participants who met initial screening criteria were contacted for a diagnostic interview. Final inclusion decisions were made at referral meetings, in which the results from the screening and interviews were evaluated. Present at these meetings were the psychology students doing the interviews, the principal responsible for the study, and the study's first author. After the intake was closed, participants were randomized and invited to start treatment. The study included four 
treatment groups: I Oroshjälpen with weekly support; II Oroshjälpen with support on demand; III A self-tailored treatment program with weekly support; IV A self-tailored treatment program with support on demand. Treatment lasted eight weeks. No control condition was included as both treatments had been tested in previous trials with positive effects. With a factorial design a comparison between all four groups as well as between main contrasts (Oroshjälpen versus selftailored treatment and weekly versus support on demand). The primary outcome measure was self-rated worry. Secondary outcomes were GAD and depressive symptoms, and quality of life. Measures were collected pre- and post-treatment.

The regional ethics committee in Umeå and Linköping, Sweden, provided ethical approval for the studies. Trial registration was done for studies II-IV at clinicaltrials.com. Staff at universities not involved in the studies handled the randomization in study II and IV. The participants in the studies did not receive any monetary compensation.

\section{Eligibility criteria and measures}

Eligibility criteria in all studies was: being age 18 years or older; being a Swedish resident; having access to a device with daily internet connection; meeting the diagnostic criteria for GAD (as a primary or secondary diagnosis); not having active suicidal ideation, or a comorbid psychiatric condition that was evaluated as too complex; no current drug or alcohol abuse; no current ongoing psychological treatment; and if on medication, currently being on a stable dosage. In studies II-IV, a score of 45 or higher on the primary measure PSWQ was necessary to be included. No cut-off score on the PSWQ was used in study I. Studies II and III also had a cut-off score on MADRS-S of 30 or less. 
Screening was done in live sessions in study I, and through online questionnaires and diagnostic interviews over the phone in studies IIIV. The administration of screening measures online has been shown to be feasible and maintain established psychometric properties of the questionnaires (Andersson, 2015). The screening measures were also used as outcome measures in all studies. The primary outcome in all studies was self-rated worry. A diagnostic interview was used at intake in all four studies, to ensure the presences of a GAD diagnosis, and at post measure in studies I, II, IV, but not in study III. Several secondary measures of anxiety and depressive symptoms were used in the studies. The presentation will focus on a selection of these measures, as several measures covers similar domains. These measures are presented in more detail below.

The primary outcome measure was the Penn State Worry Questionnaire (PSWQ). PSWQ was designed specifically to measure worry severity and is considered the gold standard when assessing worry (Meyer, Miller, Metzger, \& Borkovec, 1990). The questionnaire consists of 16 items that are answered on a five-point Likert-scale ranging from "not all typical of me" to "very typical of me", with possible scores ranging from 16 to 80 . PSWQ has good psychometric properties, with a test-retest reliability between $r=.74$ and $r=.93$, and a Cronbach's alpha between .86 and .93 .

Three secondary outcome measures were used in studies II-IV (study I did not include any secondary outcome measures). The Generalized Anxiety Disorder Questionnaire-IV (GAD-Q-IV) was used to measure GAD symptoms (Newman et al., 2002). The items in GAD-Q-IV are structured on the DSM-IV criteria for GAD and include "yes" and "no" type of questions, Likert-scales and open-ended questions. The total score range is $0-12$, with 5.7 as an optimal cut-off score when screening for GAD. The questionnaire has good psychometric properties, with a reliability of $r=.81$ and a Cronbach's alpha of .84 . 
The Patient Health Questionnaire (PHQ-9) was used to measure depressive symptoms (Kroenke, Spitzer, \& Williams, 2001). The questionnaire was designed to screen for the presence of a depressive disorder, as well as rate severity, and provide good psychometric properties. It includes nine items that are rated from 0-3, with a total scoring range of $0-27$. It also includes a rating of how much the symptoms affects the person, but that item is not included in the total score.

As a way to measure quality of life, studies II and III used the Quality of Life Inventory (QOLI) (Frisch, Cornell, Villanueva, \& Retzlaff, 1992). The questionnaire includes 16 areas that are rated on two scales: importance and satisfaction. The questionnaire has good psychometric properties, with a test-retest between .80 and .90 and a Cronbach's alpha of .82 when administrated online to a GAD population (Lindner, Andersson, Öst, \& Carlbring, 2013). Study IV used the Brunnsviken Brief Quality of Life Scale (BBQ) instead of QOLI (Lindner et al., 2016). BBQ includes 12 areas that are rated on importance and satisfaction. The questionnaire's psychometric properties are good, with a test-retest reliability of .89 and a Cronbach's alpha of .68 .

Structured diagnostic interviews were used to ensure that the participants fulfilled criteria for GAD. In studies I-III, the structural clinical interview for DSM IV (SCID, First et al, 1998) was used, which is based on the diagnostic criteria of DSM. In study IV, the Mini International Neuropsychiatric Interview (M.I.N.I), was used (Sheehan et al., 1998). Both of these interviews are semi-structured and includes specific sections for the most common psychiatric diagnoses, as specified in the DSM and international statistical classification of diseases and related health problems (ICD) respectively.

In study IV the General Self-Efficacy Scale (GSE) (Löve, Moore, \& Hensing, 2012) was used to measure effects on perceived self-efficacy. GSE includes 10 items answered on a four-point Likert-scale. The total 
score range is $10-40$ and a higher score indicates a higher perceived self-efficacy. The questionnaire has a Cronbach's alpha of .91. Study IV also included the Acceptance and Action Questionnaire II (AAQ-II) (Bond et al., 2011). AAQ-II was developed to measure psychological inflexibility or experiential avoidance, a central aspect of the theory in ACT. The measure includes seven items answered on a seven-point Likert-scale with a possible score between 7-49, and higher score indicating higher psychological flexibility. The questionnaire's testretest reliability is .81 and a Cronbach's alpha of .84 .

Study I included the Client satisfaction questionnaire (CSQ) (Larsen, Attkisson, Hargreaves, \& Nguyen, 1979) to assess satisfaction with treatment. CSQ includes eight items answered on a four-point Likertscale with a possible score between 8-32. Higher score indicates higher satisfaction with treatment. Studies II-IV included general questions about treatment satisfaction and questions about experiences tied to the treatment.

The Negative Effects Questionnaire (NEQ) (Rozental, Kottorp, Boettcher, Andersson, \& Carlbring, 2016) was used in study IV to evaluate negative experiences during treatment. NEQ consists of 32 questions answered on a four-point Likert-scale. If a negative experience is reported the respondent is asked to rate the impact of the event, and if the effect was from treatment or aspects outside of treatment. The questionnaire has a Cronbach's alpha of .95.

\section{Study samples}

Study I originally included 16 participants suffering from GAD assessed through a diagnostic interview. However, two were excluded from the analysis. Of the 14 remaining participants, $78.6 \%$ were female, and participants' mean age was 32 years. 
Study II included 103 participants diagnosed with GAD. Mean age was 39 years and $83.5 \%$ was women. Most participants were married/living with a partner (65\%), had gone to university $(79 \%)$, and were working (73.8\%). Approximately half of the population $(51.5 \%)$ was currently using medication, and $73.8 \%$ had experience of psychotherapy. Comorbid depression was present in 24 (23\%) of the participants.

Study III originally included 33 participants recruited from the control condition in study II. On participant dropped out and was excluded in the analysis. The mean age was 37.9 years, and $87.5 \%$ were women. The majority were married/living with a partner (62.5\%), had gone to university $(78.1 \%)$, and were working $(78.1 \%)$. The majority had previous experience of psychotherapy $(81.2 \%)$, and $18.8 \%$ were currently using medication.

Study IV included 85 participants with GAD as a primary or secondary diagnosis. Mean age was 41.5 years, and $82.4 \%$ was women. Most were married/living with a partner $(71.8 \%)$, had gone to university (75.2\%), and were working (62.4\%). The majority had experience of psychotherapy (70.9\%), and $25.9 \%$ were currently using medication. A large proportion $(65.9 \%)$ screened positive for one or more comorbid diagnoses at the diagnostic interview before inclusion.

Table 2 presents an overview of participants' characteristics in the studies. 
Table 2. Demographic characteristics of participants included in studies I-IV

\begin{tabular}{|c|c|c|c|c|}
\hline & $\begin{array}{l}\text { Study I } \\
(\mathrm{n}=14)\end{array}$ & $\begin{array}{l}\text { Study II } \\
(\mathrm{n}=103)\end{array}$ & $\begin{array}{l}\text { Study III } \\
(\mathrm{n}=32)\end{array}$ & $\begin{array}{l}\text { Study IV } \\
(\mathrm{n}=85)\end{array}$ \\
\hline Age, mean (SD) & $32(10.0)$ & $39.5(10.7)$ & $37.9(10.9)$ & $41.5(14.8)$ \\
\hline Gender & $\mathrm{n}(\%)$ & $\mathrm{n}(\%)$ & $\mathrm{n}(\%)$ & $\mathrm{n}(\%)$ \\
\hline Female & $11(68.8)$ & $86(83.5)$ & $28(87.5)$ & $70(82.4)$ \\
\hline Male & $3(21.4)$ & $17(16.5)$ & $4(12.5)$ & $15(17.6)$ \\
\hline \multicolumn{5}{|l|}{ Marital status } \\
\hline Single & - & $21(20.4)$ & $7(21.9)$ & $20(23.5)$ \\
\hline $\begin{array}{l}\text { Married/ } \\
\text { cohabiting }\end{array}$ & - & $67(65)$ & $20(62.5)$ & $61(71.8)$ \\
\hline Other & - & $15(14.6)$ & $5(15.6)$ & $4(4.7)$ \\
\hline \multicolumn{5}{|l|}{ Education } \\
\hline Elementary school & - & $2(1.9)$ & 0 & $2(2.4)$ \\
\hline High school & - & $22(21.4)$ & $7(21.9)$ & $13(15.3)$ \\
\hline University & - & $79(76.7)$ & $25(78.1)$ & $64(75.2)$ \\
\hline Other & - & 0 & 0 & $6(7.1)$ \\
\hline \multicolumn{5}{|l|}{ Occupation } \\
\hline Student & - & $12(11.7)$ & $3(9.4)$ & $12(14.1)$ \\
\hline Working & - & $76(73.8)$ & $25(78.1)$ & $53(62.4)$ \\
\hline Other & - & $15(14.6)$ & $4(12.5)$ & $20(23.5)$ \\
\hline \multicolumn{5}{|l|}{ Medication } \\
\hline Never & - & $50(48.5)$ & $16(50)$ & $51(60)$ \\
\hline Currently & - & $53(51.5)$ & $6(18.8)$ & $22(25.9)$ \\
\hline \multicolumn{5}{|l|}{ Psychotherapy } \\
\hline Never & - & $27(26.2)$ & $6(18.8)$ & $25(29.4)$ \\
\hline Previous & - & $76(73.8)$ & $26(81.2)$ & $60(70.6)$ \\
\hline
\end{tabular}




\section{Interventions}

All studies included the acceptance-based treatment program called Oroshjälpen'. Oroshjälpen includes elements from traditional CBT (functional analysis of behaviour and exposure to anxiety-evoking stimuli), but the principal components are acceptance, mindfulness, and valued action, and all interventions are presented in a way that corresponds with these principles. The exposure elements are for example not done with a habituation rationale but suggested as a way to invite unpleasant sensations, thoughts and feeling without manipulation and with an accepting stance. Theoretically, it can be viewed as a part of the third wave of CBT, i.e., ACT and ABBT for GAD. The components and structure of the program are presented in Table 3.

Guiding principles in the design of the program was to keep the texts short and to integrate animations, film clips, and exercises to make the content as easily accessible as possible for the user. The modules are arranged in a fixed order building upon each other to facilitate a gradually deeper understanding of worry as progress is made through the treatment. The same principle is applied in the accompanying exercises, which aim to teach and strengthen the user's ability to choose behaviours other than worry and avoidance step-by-step. The user has access to the whole program from start, but must go through the present module to get access to the next one. The program includes four rating scales presented at the start of each module as a way to help the user, and the support, track changes during treatment.

Between studies III and IV, the program went through some minor revisions. In the first version of the program, a separate workbook (in paper or pdf) and a CD with audio files (the same as in the program) were sent to the user. In the second version of the program the

${ }^{1}$ Psykologpartners, a private company, owns the program Oroshjälpen. 
workbook was integrated into the program. The first version included four scales that were answered on a sliding scale: level of worry; anxiety; tension; and quality of life in the past week. In the later version, the scales were changed to the following questions: "How much worry have you had the past week?", "How many days the past week have you felt satisfied with your life?", "How often have you done what is important to you the past week?", and "How often have you worked with the exercises the past week?" These scales were answered on a four-point Likert-scale.

Table 3. Structure and content of the treatment program Oroshjälpen

\begin{tabular}{lll}
\hline Module & $\begin{array}{l}\text { Content } \\
1\end{array}$ & Exercises \\
\hline $\begin{array}{l}\text { Introduction to the treatment program } \\
\text { and psychoeducation about worry and } \\
\text { anxiety. }\end{array}$ & $\begin{array}{l}\text { Examine own anxiety, } \\
\text { worry, and coping } \\
\text { strategies. }\end{array}$ \\
& $\begin{array}{l}\text { Functional analysis } \\
\text { Functional analysis, avoidance, and } \\
\text { short-term effects are presented as a } \\
\text { way to understand worry and other } \\
\text { behaviours. }\end{array}$ & $\begin{array}{l}\text { Analysis of own worry } \\
\text { and other behaviours with } \\
\text { the help of functional } \\
\text { analysis. }\end{array}$ \\
& $\begin{array}{l}\text { Values and activities } \\
\text { Values and value-based action are } \\
\text { presented as an alternative to } \\
\text { avoidance and control strategies. }\end{array}$ & $\begin{array}{l}\text { Clarify own values and } \\
\text { schedule valued activities. }\end{array}$ \\
$\begin{array}{l}\text { Mindfulness } \\
\text { Mindfulness is introduced as a way to } \\
\text { be in the present moment instead of } \\
\text { getting stuck in a struggle with worry } \\
\text { and judgment, or reacting to anxiety. }\end{array}$ & $\begin{array}{l}\text { Practice mindfulness with } \\
\text { the help of audio files and } \\
\text { in daily activities. }\end{array}$ \\
$\begin{array}{l}\text { Worry as a process } \\
\text { Based on previous modules, worry is } \\
\text { conceptualized as a constant struggle } \\
\text { in the service of avoidance. }\end{array}$ & $\begin{array}{l}\text { Through mindfulness, } \\
\text { actively notice the worry } \\
\text { process, invite unpleasant }\end{array}$ \\
\hline 5 &
\end{tabular}


Acceptance is introduced. The user is encouraged to give up the struggle for control and invite unpleasant thoughts and feelings without manipulation.

6 experiences, and let values guide actions instead of control strategies.

Practice mindfulness, acceptance, and valued action in the daily life.

Structure a personal plan on how to continue practice and develop the skills learned during the treatment.

A self-tailored treatment was tested in study IV. ICBT tailored to individual problems by the therapist has been tested in several trials with positive effects (Păsărelu, Andersson, Bergman Nordgren, \& Dobrean, 2017). Self-tailored ICBT has shown promising results in a pilot trial (Andersson, Estling, Jakobsson, Cuijpers, \& Carlbring, 2011). Participants randomized to self-tailored treatment were given access to short descriptions of 14 treatment modules. Based on the description of the modules and the individual problems the participant struggled with, they were instructed to choose the seven modules they thought suited them best. The participants were encouraged to include the introduction and relapse-prevention modules among the seven modules, but they were not mandatory. The 14 modules address different aspects of psychological problems and treatment components. The modules were taken from previous treatment studies by our research group and were all based on CBT principles that are viewed as evidence-based. Some of the modules are based on material developed for the previous treatment of GAD tested in the trials by Paxling et al. (2011) and Anderson et al. (2012). All modules included psychoeducation, one or more treatment principles, and appropriate 
exercises that the participants were instructed to work with. The modules were modified slightly in terms of language and structure to work as independent modules and suit individuals with worry as their primary concern.

Two online treatment platforms were used in the studies. In studies IIII, a platform designed by the company Psykologpartners was used for delivery of the treatment program. The platform was designed specifically to deliver internet-based treatments. The conceptual idea behind the platform was that it should be easy to use and be able to include animations, video, and audio. The therapist section of the platform makes it possible for the support to see the participants' ratings in the program, number of logins and time spent with the program. This platform had no message function or the possibility to include questionnaires. The online measures and text-based communication were delivered through a secure platform hosted by Linköping University (Iterapi), developed to deliver internet-based treatments, questionnaires, and text-based communication securely (Vlaescu, Alasjö, Miloff, Carlbring, \& Andersson, 2016). In study IV, the Iterapi platform developed at the university was used for delivery of all treatment material, questionnaires, and communication.

\section{Support}

Weekly support was used in studies I, II, and III, in which participants were instructed to send a report by the end of each week with information about experiences during that week's work with the program and exercises. They also could ask questions related to the treatment program during the week. The support replied within 24 hours (except on weekends). The reply was structured around problemsolving, validation, and encouragement. Another guiding principle was not to add additional treatment material in the replies, but only refer to the treatment program while clarifying aspects if needed. Finally, the 
support was instructed to send a message to participants if they failed to send a report and ask how the work was progressing. The support was given instructions to try and limit time spent with each participant to no more than 15 minutes.

Support on demand was used in studies III and IV, in which participants were instructed to work on their own with the treatment program, and contact the support if they needed help or had any questions about the treatment. No messages were sent to a participant if they did not initiate a contact.

Automated messages were used in study III. The messages were written before the treatment started and sent on a pre-determined schedule. All participants received the messages at the same time. The messages were written as short reminders and included one or more of the following topics: information on how many weeks remained of the treatment; encouragements; highlights from the current treatment module; reminders to work with the exercises.

Two licensed psychologists working at the primary care clinics provided support in study I. In studies II-IV, final year psychology students under supervision provided support. Messages were sent through the treatment platforms in studies II, III, and IV, and through secure e-mail in study I.

\section{Data analyses}

In study I, changes on the outcome measure from pre- to posttreatment and follow-up were analysed with paired-samples $t$-test. Two of the original 16 included participants were excluded from the analysis. One dropped out before treatment started, and another used medication that was an exclusion criterion. All analyses were performed with the program SPSS. 
In study II, demographic and pre-treatment variables were analysed with Fisher's exact test and independent samples $t$-test. The outcome measures were analysed using hierarchical linear modelling and fitted with maximum-likelihood estimations. A two-part piecewise growth model was used to analyse change from post-measure to follow-up to evaluate whether changes during treatment and the follow-up period differed. Missing data were handled with the intention to treat principle with all randomized participants included in the analysis. All analyses were performed with the program R 3.0.2. Clinical significance was measured using the Jacobson and Truax (1991) approach. Norm data from Gillis, Haaga, and Ford (1995) and clinical data from Behar, Alcaine, Zuelling and Borkovec (2003) were used to calculate a cut-off score on the primary outcome measure PSWQ. However, as stated below, another calculation was used in the presentation in the thesis to enable comparisons between the studies.

In study III, changes in outcome measures from baseline, and pre- to post- were analysed with paired-sample $t$-tests. On participant failed to answer post measures and was excluded from analyses. All analyses were performed using the SPSS program.

In study IV, one-way ANOVA was used to examine whether significant differences existed between the four groups on any pretreatment measures, as well as measures on satisfaction with treatment. Differences in demographical aspects were investigated with Chi2, which also was used to investigate differences between the groups in post-measure completion, adherence, and recovery rates. Within-group effects from pre- to post-measure, interaction effects, and the main effects of treatment conditions and support forms were investigated with repeated-measures ANOVA. Due to the low number of participants, the study only had enough statistical power to detect moderate effects $(d=0.50)$, for the main effects/contrasts given $80 \%$ power and an alpha level of 5\%. Missing data were handled through 
multiple imputation in SPSS and intention to treat analysis. Following the Schafer and Graham's (2002) recommendation, 20 imputations were made, and the pooled results were used in the repeated-measures ANOVAs.

Clinical significance was calculated using the Jacobson and Truax (1991) approach, according to which two criteria must be met to consider a participant recovered. First, the participant must make a statistically reliable change in the outcome measure, and second, the participant should have a score below a clinical cut-off on the measure. In study II, a reliable change score and cut-off were calculated. In study IV, the criteria that Fisher (2006) formulated was used for reliable change and as a PSWQ cut-off. Fisher argued that reliable change and clinical significance should be standardized for specific measures to make results from different studies easily comparable. According to Fisher, reliable PSWQ change must entail a change of seven or more points, and an appropriate clinical cut-off is 47 points on the PSWQ. Recovery is defined by meeting both these criteria. In this thesis, the presentation of reliable change and recovery rates was done with the criteria by Fisher. Calculations were done in all studies even if they were not presented in the original article as a way to compare the effects more easily.

Effect sizes in all studies were calculated using the Cohen's $d$ approach. Within-effects were calculated by subtracting the average score on the pre-treatment measure from the average score on the posttreatment measure, then dividing the result with the pooled standard deviation. Between-group effects were calculated by subtracting the average score on the post-measure in one group from the average score on the post-measure in the other group, then dividing the result by the pooled standard deviation from the groups. 


\section{Results}

\section{Study I}

Study I included 16 participants in a within-group design with pre-, post-, and two- to three-month follow-up measures. Two participants were excluded from data analysis. One never started treatment and the other used medication that was an exclusion criterion in the study.

\section{Primary outcome}

A statistically significant large within-group effect was observed at post-treatment on the PSWQ (Cohens $d=2.14$ ). Follow-up data were collected from 10 of the 14 participants, indicating that results were maintained. Reliable change was seen in 13 (92.8\%) of the participants and $8(57.1 \%)$ were rated as recovered at post-treatment. No participant showed a clinically significant deterioration.

\section{Secondary outcome}

Diagnosis was established through a clinical interview. Upon inclusion, all participants meet the DSM-IV criteria for GAD. At postmeasure and follow-up, $80 \%$ did not meet the diagnostic criteria.

\section{Treatment evaluation}

All 14 participants completed all modules in the treatment. On average, participants accessed the program $12.1(\mathrm{SD}=4.1)$ times, sent 8.8 (SD 3.3) e-mails to support, and received $9.4(\mathrm{SD}=4.0)$ responses. The treatment time was on average 103 days $(\mathrm{SD}=40.4)$. Treatment satisfaction as measured with the CSQ was high, $20.78(\mathrm{SD}=2.63)$. 


\section{Study II}

Study II included 103 participants randomized to treatment or a waiting-list control group. Post-treatment measures were collected from $80.8 \%$ in the treatment group and $84.3 \%$ in the control group. Follow-up measures were collected from $61.5 \%$ of the treatment group six months after treatment. Statistically significant between-group effects were found on all measures, except for quality of life. Betweenand within-group effect sizes were medium to large on all outcomes except for QOLI, which showed a small effect.

\section{Primary outcome}

Hierarchical linear modelling showed a significant between-group effect in favour of the treatment group $(b=-0.86,95 \%$ [CI -1.23 , $0.48])$ on PSWQ. Between-groups effects were large $(d=0.87)$. Within-group effects in the treatment group were large at post-measure $(d=1.35)$ and at follow-up $(d=1.71)$. A significant effect from posttreatment to follow-up was observed in the treatment group $(b=-0.10$, $95 \%$ [CI $-0.17,-0.03])$, indicating that the participants continued to improve after treatment. In the treatment group, 23 participants (44\%) made a reliable change, and $11(21 \%)$ met the criteria for recovery (intention to treat). In the control group, 3 participants $(6 \%)$ met criteria for recovery. No participant showed a clinically significant deterioration.

\section{Secondary outcomes}

Change in GAD symptoms were evaluated with the GAD-Q-IV using hierarchical linear modelling. Results showed a significant betweengroups effect in favour of the treatment group $(b=-1.78,95 \%$ [CI $2.68,-0.78])$. The between-group effects were $d=0.70$. Within-group effects in the treatment group were large at post-treatment $(d=1.50)$ and at follow-up $(d=3.91)$. A significant effect from post-treatment to follow-up was observed in the treatment group $(b=-0.06,95 \%$ [CI - 
$0.09,-0.03])$ indicating that the participants continued to improve after treatment.

Depressive symptoms were measured with PHQ-9. Hierarchical linear modelling showed significant between-groups effects in favour of the treatment group ( $b=-26.22,95 \%$ [CI $-45.86,-6.08])$. Betweengroups effects were moderate $(d=0.51)$. Within-group effects in the treatment group were large at post-treatment $(d=1.01)$ and at followup $(d=1.03)$. There was no significant effect from post-treatment to follow-up in the treatment group $(b=-0.007,95 \%$ [CI $-0.04,-0.02])$, indicating that effects were maintained but did not continued to improve after treatment.

Effects on life quality were measured with the QOLI. No significant between-groups effects were observed in the average linear change over time $(b=0.05,95 \%[\mathrm{CI}-0.01,-0.10])$. Between-groups effects were small $(d=0.12)$. Within-group effects in the treatment group were moderate at post-treatment $(d=-0.52)$ and at follow-up $(d=-$ 0.66). A significant effect from post-treatment to follow up was observed in the treatment group, $(b=-0.01,95 \%$ [CI $-0.002,-0.02])$ indicating that the participants continued to improve after treatment.

\section{Treatment evaluation}

A large proportion of the participants, $76 \%$ completed all modules during treatment. Treatment satisfaction was high, with $92.5 \%$ being satisfied, and $64.2 \%$ rating the supportive contact as important. Average time spent on support for each participant per week was 9.6 minutes, and during whole treatment 78.78 minutes (range: 1-226 minutes). 


\section{Study III}

Study III included 33 participants, with post-treatment measures collected from 32 (97\%) participants. Prior to starting treatment, the participants were in a control condition in study II for nine weeks. Results showed that significant changes occurred during that time. At post-treatment results showed significant moderate to large withingroup effects $(d=0.84-2.71)$ on all measures included in the study, except for QOLI, which showed a small effect $(d=-0.34)$ from pre-to post-treatment.

\section{Primary outcome}

Significant differences in PSWQ from pre- to post-treatment, $(t[31]=$ $6.0, p=.001)$, with a large effect $(d=1.17)$, were observed. Reliable change was seen in 23 (71.9\%) of the 32 participants and 14 (43.8\%) were rated as recovered. One participant showed deterioration.

\section{Secondary outcomes}

Change in GAD symptoms from pre- to post-treatment evaluated with the GAD-Q-IV showed a significant effect $(t[31]=9.4, p=.001)$ with a large effect size $(d=2.71)$.

Change in depressive symptoms from pre- to post-treatment, evaluated through PHQ-9 showed a significant effect $(t[31]=6.0, p=.001)$ with a large effect size $(d=1.05)$.

Effects on quality of life from pre- to post-treatment evaluated through QOLI showed a significant effect $(t[31]=-2.2, \mathrm{p}=0.034)$ with a small effect size $(d=-0.34)$.

\section{Treatment evaluation}

Of the 32 participants, $19(59.3 \%)$ completed all modules during treatment. Nine participants $(28.1 \%)$ contacted support with treatment- 
related questions, and $12(37.5 \%)$ with technical questions. Five $(15.6 \%)$ of these asked questions in both categories. On average, the participants logged in 9.68 times (range 2-27 times, $\mathrm{SD}=6.43$ ) during the treatment. The total time used by the support during the treatment was 59 minutes for treatment-related questions and 68 minutes on technical support. On average, the support spent 6.2 minutes per participant during the treatment. Twenty-three participants (72\%) rated the possibility of getting support as good. Furthermore, 25 (78.2\%) participants rated the automated messages as positive and three $(9.4 \%)$ as not that positive. A large proportion of the participants, $24(75 \%)$, were satisfied with the treatment, and two $(6.4 \%)$ not satisfied. A majority, $28(87.5 \%)$ rated the content of the treatment program as good or very good and $(93.8 \%)$ rated the program as educational and easy to use.

\section{Study IV}

Study IV included 85 participants who were randomized to four different treatments (I: Oroshjälpen with scheduled weekly support; II: Oroshjälpen with support on demand; III: Self-tailored treatment with scheduled weekly support; or IV: Self-tailored treatment with support on demand). Post-treatment measures were collected from 65 (76.5\%) participants, and 59 (69.4\%) went through a diagnostic interview after treatment. There was no significant difference in rates of noncompleters between the four groups $\chi^{2}(3, N=85)=1.599, p=.66$. Significant within-group effects, with small to large effect sizes, were observed on all measures included in the study in all groups. No significant differences were observed on any outcome measure between the four groups or main contrasts.

\section{Primary outcome}

Repeated-measures ANOVA on the PSWQ showed a significant within-group effect from time $(F[1,81]=127.47, \quad p<.001)$. No 
significant effects were found from treatment format, type of support, or interaction between treatment and support. Moderate to large within-group effects were observed in all groups: Oroshjälpen with weekly support $(d=1.43$ [CI $95 \%=0.99-1.86])$, Oroshjälpen with support on demand $(d=0.86$ [CI $95 \%=0.51-1.21])$, self-tailored treatment with weekly support $(d=0.77$ [CI 95\%=0.42-1.11]), and self-tailored treatment with support on demand $(d=0.95$ [CI $95 \%=$ $0.60-1.31])$. The within-group effect calculated on the whole sample receiving Oroshjälpen was $d=1.28$ [CI $95 \%=1.08-1.49$ ], and for self-tailored treatment $d=1.00$ [CI 95\%=0.52-1.00]. Within-group effects for the whole sample receiving weekly support were $d=1.22$ [CI $95 \%=0.93-1.50$ ], and for support on demand $d=0.80$ [CI $95 \%=$ $0.56-1.04]$. Between-groups effects for the two types of support were $d=0.14$ in favour of weekly support, compared with support on demand. Between-groups effects for treatment were $d=0.10$ in favour of Oroshjälpen compared with self-tailored treatment.

Of the 65 participants completing post-treatment measures, $40(61.5 \%)$ made a reliable change based on PSWQ, and with intention to treat analysis $47 \%$. No participant showed reliable deterioration. Recovery was seen in $17(26.2 \%)$ of the 65 participants and in $20 \%$ with the intention to treat analysis. In the Oroshjälpen with weekly support condition 7 of 21 participants were recovered, 4 of 22 in the selftailored and support on demand condition and 3 of 21 in the remaining two groups There was no significant difference between the two treatments $\left(\chi^{2}[1, N=65]=.0598, p=.44\right)$ or the two support types $\left(\chi^{2}\right.$ $[1, N=65]=3.188, p=.74)$ in rates of clinically significantly improvement.

\section{Secondary outcomes}

Repeated-measures ANOVA showed a significant within-group effect from time on GAD-Q-IV $(F[1,81]=43.94, p<.001)$. No significant effects were found for treatment format, type of support, or treatment 
and support combined. Within-group effects (Cohen's $d$ ) in the four groups were: $d=1.17$ for Oroshjälpen with weekly support, $d=0.92$ for Oroshjälpen with support on demand, $d=0.65$ for self-tailored program with weekly support, and $d=0.39$ for self-tailored and support on demand.

Repeated-measures ANOVA showed a significant within-group effect from time on depressive symptoms measured with PHQ-9 $F[1,81]=73.15, p<.001$. No significant effects were found for treatment format, type of support or treatment and support combined. Withingroup effects (Cohen's $d$ ) in the four groups were: $d=1.44$ for Oroshjälpen with weekly support, $d=1.04$ for Oroshjälpen with support on demand, $d=1.11$ for self-tailored program with weekly support, and $d=0.66$ for self-tailored and support on demand.

Repeated-measures ANOVA showed a significant within-group effect from time on quality of life, measured with BBQ $F[1,81]=22.68$, $p<.001$. No significant effects were found for treatment format, type of support or treatment and support combined. Within-group effects (Cohens $d$ ) in the four groups were: $d=-0.44$ for Oroshjälpen with weekly support, $d=-0.52$ for Oroshjälpen with support on demand, $d$ $=-0.49$ for self-tailored program with weekly support, and $d=-0.38$ for self-tailored and support on demand.

Of the 85 included participants, 58 completed the post-treatment clinical interview with MINI. After treatment, $48(82.8 \%)$ of the 58 participants did not meet diagnostic criteria for GAD and $66 \%$ with an intention to treat analysis. There was a significant difference between treatment type received $\left(\chi^{2}[1, N=58]=3.869, p=.049\right)$ and not fulfilling criteria for GAD in favour of Oroshjälpen, but not for support type $\left(\chi^{2}[1, N=58]=1.330, p=.249\right)$. Five of the ten participants still fulfilling the criteria for GAD were in the self-tailored treatment with support on demand condition, three in the self-tailored with scheduled 
support condition, two in the Oroshjälpen with support on demand and none in the Oroshjälpen with scheduled support condition. Three participants $(5.2 \%)$ meet the criteria for current depressive episode, two in the Oroshjälpen with support on demand condition and one in the self-tailored treatment with weekly support condition. A clinical rating of improvement, based on the Clinical Global Impression Improvement scale (CGI-I) (Guy, 1976), was done during the interviews. Of the 58 participants, $48(82.7 \%)$ were rated as improved, $7(12.1 \%)$ no change, and $3(5.2 \%)$ worse. There was no significant difference between the four groups $\left(\chi^{2}[6]=7.90, p=.246\right)$. The ratings were similar to the participants' own ratings on the same scale in the post-treatment measures, as $54(83.1 \%)$, of the 65 completers rated an improvement, 8 (12.3\%) no change, 3 (4.6\%) felt worse, with no significant difference between the groups $\left(\chi^{2}[6]=7.63, p=.267\right)$.

Repeated-measures ANOVA showed a significant within-group effect from time on psychological flexibility, measured with AAQ $(F[1,81]=20.55, p<.001)$ in all groups, with small to moderate effects (Cohens $d=0.22-0.69$ ). No significant effects were found for treatment format, type of support or treatment and support combined. Furthermore, a significant within-group effect from time on selfefficacy, measured with $\operatorname{GSE}(F[1,81]=12.31, p<.01)$ was seen in all groups, with small to moderate effects (Cohens $d=0.13-0.44$ ). No significant effects were found for treatment format, type of support or treatment and support combined.

\section{Treatment evaluation}

In the whole sample, 50.8\% completed all modules during treatment. There was a significant difference between the groups in completion of the whole treatment in favour of Oroshjälpen with scheduled support $\left(\chi^{2}[3]=9.41 p=.024\right)$. In the Oroshjälpen with scheduled support condition 12 of the 15 completers $(80.0 \%)$ finished all modules (range within group: 5-7), 10 of 18 (55.6\%) in the Oroshjälpen and support on 
demand condition (range within group: 2-7), 4 of 15 (26.7\%) in the self-tailored with scheduled support condition (range within group: 07 ), and 7 of $17(41.2 \%)$ in the self-tailored and support on demand condition (range within group: 1-7). The average time spent on support per participant was $5.6(\mathrm{SD}=3.4)$ in the support on demand conditions and $59.9(\mathrm{SD}=8.0)$ in the scheduled support conditions.

Overall, 59 of the $65(90.8 \%)$ completers were satisfied or very satisfied with the treatment. There was a significant difference between the four groups on satisfaction with treatment as a whole $(F[3,61]=3.12, p=.032)$. Further analysis showed that it was an effect from type of support received $(F[3,61]=9.56, p=.03)$ in favour of scheduled weekly support, and no significant effect from treatment program $(F[3,61]=0.62 .12, p=.80)$. There was a significant difference between the four groups on satisfaction with treatment program $(F[3,61]=5.82, p=.001)$. Further analysis showed that type of support, in favour of scheduled weekly support $(F[3,61]=11.19, p=.001)$, and of the treatment program $(F[3,61]=4.16, p=.046)$, in favour of selftailored treatment, had significant effects on positive evaluation of the treatment program received. There was a significant difference between the four groups on satisfaction with support $(\mathrm{F}[3,61]=7.31$, $p=.001)$. Further analysis showed that it was an effect from support type $(F[3,61]=22.36, p=.001)$ in favour of weekly support and no significant effect from treatment program $(F[3,61]=0.003, p=.96)$ received. Experiences of adverse events during treatment were collected post treatment. Most frequent adverse events reported were stress, more anxiety, unpleasant memories or feelings, and not understanding the treatment. There were no significant differences between the four groups in ratings of negative experiences during treatment. 


\section{Discussion}

\section{Main findings}

The overall aim of this thesis was to examine the effects of a novel internet-based treatment for GAD. The treatment was based on acceptance, mindfulness, and committed action, in contrast to many existing ICBT programs for GAD that are based on traditional CBT components, such as cognitive restructuring, relaxation, and management strategies for secondary problems associated with GAD. The treatment program was delivered with two types of support, weekly support or support on demand to investigate how different types of support impacts treatment outcomes.

\section{Outcome measures and diagnosis}

A first step in developing a new treatment is to evaluate the treatment on a smaller scale, as was done in study I. Results showed a large effect on self-rated worry, high satisfaction of treatment, and no participants showed a significant deterioration at post-treatment. Furthermore, $80 \%$ of participants did not meet diagnostic criteria posttreatment, and treatment effects were maintained at follow-up. Study II was a randomized controlled trial comparing Oroshjälpen against a wait list control condition. Large within-group effects were seen on the primary outcome (PSWQ), and moderate to large effects on secondary outcomes on GAD- and depressive symptoms and quality of life. Follow up data indicated that the effects were maintained, or improved at six-month follow-up. Receiving treatment was significantly better than the waiting list condition, with moderate to large between-groups effects on primary, and secondary outcomes. The within-groups effects from study II was replicated in study III reporting similar effects. The within- and-between groups effects reported in study I-III are 
comparable to effects from other internet-based treatments for GAD (Titov et al., 2016), as well as face-to-face treatments (Stefan et al., 2019) indicating that Oroshjälpen is an effective treatment.

In study IV, the effects of Oroshjälpen was compared with an active treatment. The treatment program compared to Oroshjälpen was a selftailored program where participants selected 7 out of 14 possible modules based on personal preferences. All modules included evidence-based CBT principles for GAD, anxiety, depression, or other common problems associated with GAD such as sleeping problems. Tailoring the treatment received to one's own preferences and concerns could have a positive effect on adherence and treatment outcomes. In a meta-analysis by Păsărelu et al. (2017), tailored internet-based treatments showed significant and large effects on primary and secondary outcomes for populations with mixed anxiety and depressive symptoms, including GAD. Compared with disorderspecific treatments, no significant differences were found on anxiety outcomes, but significant differences were found on depressive and quality of life outcomes in favour of tailored treatments. In study IV no significant between-group differences were observed on primary or secondary self-rated outcome measures. However, there was a significant difference in not meeting GAD criteria at post-treatment diagnostic interviews in favour of Oroshjälpen, with $94.9 \%$ of those completing the post-treatment interview not meeting the criteria. Regarding effect sizes Oroshjälpen, especially in combination with weekly support, showed larger within-group effect sizes across several outcome measures. Study IV gives preliminary indications that Oroshjälpen provides similar effects as an active treatment on primary outcomes. Furthermore, Oroshjälpen might be equally effective in treating comorbid conditions as a treatment specifically designed to address comorbid conditions trough tailoring the treatment to individual needs. However, the study was not sufficiently powered to detect small differences and the results should be interpreted with caution. The short-term effects are similar to a study by Dear et al. 
(2015), comparing a disorder-specific treatment vs. a transdiagnostic treatment and self-guided vs. clinician guided treatments for GAD. No significant differences were found between the different treatments post-treatment. However, at long term follow-up the transdiagnostic treatment showed larger reductions in GAD symptoms and depressive symptoms. A long term follow-up on study IV would provide valuable information in comparison to the study by Dear et al. A recent study by Andersson et al. (2020) compared a worry-specific treatment with a stress management program based on applied relaxation, with $90 \%$ of participants fulfilling a GAD diagnosis. In that study, the worryspecific treatment was more effective than the control condition. However, in study IV, the active treatment compared with Oroshjälpen included one or more of the strategies acceptance, cognitive restructuring, exposure, emotion regulation, and relaxation amongst other strategies, which all are viewed as vital elements in CBT protocols for GAD. The results from study IV should be explored further, by comparisons to an established treatment and with larger sample to give more robust indications.

Clinically significant changes are important to consider, perhaps especially in clinical settings. Besides effect sizes and significance testing it provides an indication of the treatments impact on the individual. On average, reliable change was seen in approximately $65 \%$ of all participants included in this thesis, and approximately $34 \%$ were rated as meeting high end state functioning or recovered. Different criteria for defining responders are used in different studies making comparisons to other studies difficult (Loerinc et al., 2015). However, the effects reported in this thesis are similar to those reported in a large study on clinical effects of ICBT treatments concluding that about one third reach remission post-treatment (Andersson, Carlbring, \& Rozental, 2019). In a meta-analysis examining response rates in face-to-face treatment the response rate of CBT for GAD was $47 \%$ on average (Loerinc et al., 2015). However, if using intention to treat analysis and the Jacobsen and Truax approach 
the response rates was considerably lower. A more recent metaanalysis showed similar effects, with $51 \%$ of GAD cases showing remission at post-treatment (Springer, Levy, \& Tolin, 2018). A large proportion across the studies in this thesis did not met diagnostic criteria for GAD post treatment, and in study IV $83 \%$ rated themselves as improved. Only one participant made a reliable deterioration, which can be considered low (Rozental, Magnusson, Boettcher, Andersson, \& Carlbring, 2017). The clinical indications of this is that when treating individuals with GAD Oroshjälpen helps individual participants make clinically relevant changes in worry severity, and a large proportion do not meet criteria for GAD after approximately nine weeks of treatment. Furthermore, the effects are not that different from face-to-face treatments for GAD, requiring more time and skills from therapist, indicating that an acceptance-based treatment delivered online can be a viable option in first line treatment of GAD.

Compared with the effects on symptoms measures included in the studies, a weaker effect was seen on quality of life. Significant, with small to moderate, within-group effects were reported in studies II-IV. In study II, a non-significant between-groups effect $(d=0.12)$, compared with the waiting-list control group was found. Significant and small to moderate effects was seen in both treatments in study IV, with non-significant differences between the two. Finding a smaller effect on quality of life is not that surprising. A meta-analysis by Hofmann, Wo, and Boettcher (2014) indicated that the impact on quality of life when delivering CBT for anxiety disorders is moderate. Furthermore, the effects were significantly lower for internet-based treatments compared with face-to-face treatments, and longer treatments yielded greater effects. The within-group effect on quality of life for patients with GAD was smaller than for all other included disorders $(g=0.43)$, and in the same range as the effects seen in this thesis. However, in the meta-analysis on internet-based treatments for GAD by Richards et al. (2015), a significant between-groups effect of $(d=0.38)$ was found for treatment compared with control conditions. 
The weaker effects and somewhat conflicting results in this thesis indicate that there is still room for improvements regarding effects on quality of life.

In addition to symptoms measures study IV also included measures of psychological flexibility and self-efficacy. Oroshjälpen had a significant effect on psychological flexibility, which is one of the central theoretical concepts in acceptance-based treatments. This indicates that Oroshjälpen helps the patients become more open to having negative experiences without reacting on them automatically with avoidance. Furthermore, the treatment had significant effects on perceived self-efficacy indicating that going through the treatment can help the patient develop or strengthen a sense of mastery. Both these aspects are theoretically central for how a patient tackle obstacle in life and become more resilient. However further research is needed to understand how these aspects are influenced by the treatment and what it actually means for the patient.

\section{Effects of different types of support}

In addition to investigating overall clinical effects the thesis aimed to examine the effects of Oroshjälpen delivered with different types of support. Study III indicates that the treatment program can be delivered with support on demand and automated messages with within-group effects similar to the effects seen in study II, using weekly support. Furthermore, no significant differences were found in study IV between the different types of support on outcome measures. A small $(d=0.14)$ non-significant effects in favour of weekly support was observed. However, even if the two types of support do not have a significantly different impact on outcome measures, support type seems to impact other treatment aspects. Completion rates (defined as completing all modules during treatment) were approximately 57\% when receiving support on demand (study III and IV) compared with 
approximately $78 \%$ when receiving weekly support (study II and IV). In study IV, the range of modules accessed during treatment was 5 to 7 in Oroshjälpen and weekly support, and 2 to 7 in Oroshjälpen and support on demand. This indicates that those receiving weekly support also access more modules, even if they do not complete the whole treatment. These results are in line with other recent studies indicating a higher rate of completers with weekly support (Hadjistavropoulos et al., 2019). It seems that weekly support has some aspects that makes the participant, at least access, more modules during treatment. Perhaps this is not surprising considering that participants receiving weekly support are instructed to send reports each week and ask questions about the treatment if needed. The reports are answered in 24 hours with helpful tips if needed and encouragements to keep on working. Furthermore, participants are contacted if not sending a report. These social aspects of an ongoing validating and somewhat demanding interaction might be important to help those starting to drop out stay on track. When receiving support on demand no such control functions or social aspects are present. The contact is initiated by the participant and even if contact is initiated it stops after the problem at hand is solved. In this regard support on demand is more dependent on the participants own motivation to keep on working with the program. However, it is worth noting that regardless of support type more participants receiving Oroshjälpen completed the whole treatment compared to the self-tailored treatments in study IV. Compared to the median of $66 \%$ completers in the meta-analysis by Andrews at al. (2018), 57\% completers with support on demand is still quite good and $78 \%$ with weekly support in the upper range.

In study IV experiences of adverse events during treatment was collected post-treatment. The most common response reported was stress, and another frequent response was not understanding treatment material. Participants also reported having unpleasant memories and anxiety. All these responses are to some degree expected in ICBT treatments for GAD, and influence adherence (Johansson, Michel, 
Andersson, \& Paxling, 2015). But even if they can be expected, the reported adverse events raise important questions of how they can be addressed through the provided support. If a certain type of negative experience is reoccurring it is possible that guidelines for support should include some aspects of raising certain questions with patients before or during treatment to be proactive. By doing so some possible hindering effects could be addressed, and maybe even solved.

Treatment satisfaction was high in all studies, indicating that the treatment was acceptable for the participants regardless of support type. However, in study IV receiving weekly support had a significantly positive impact on satisfaction with support, treatment program and treatment as a whole, compared with support on demand. This could possibly be an important aspect influencing the participants interaction with the program, in regard to how much work they put in and how much of the program they access. Another aspect of delivery of support is how it affects the psychologist providing the support. Total time spent, on average, per participants when delivering support on demand were approximately 6 minutes in studies III and IV and 69 minutes on average when delivering weekly support in studies II and IV. None of these treatments are time consuming compared to face-toface treatments, but for a clinician delivering support it can make a big difference. When delivering weekly support, you need to be prepared each week to receive a report and write an answer that is validating and meaningful. Weekly support often also includes a more active monitoring process and prompting reports if they are not sent to the psychologist. In support on demand on the other hand, the contact is initiated by the patient when needed, making it potentially less burdensome for the psychologist and more cost-effective.

In summary, the results presented in this thesis strengthen previous research indicating that treatments based on acceptance, mindfulness, and valued action can be effective treatments for a range of psychological concerns, and in this case in the treatment of GAD with 
an internet-based program. The clinical implications of the results indicate that an acceptance-based online treatment is effective in reducing worry, the principal criteria in GAD, and other GAD related symptoms, as well as comorbid depressive symptoms. Furthermore, a large proportion of the participants in the included studies do not meet diagnostic criteria post treatment and improvements are maintained or improved at six-months follow-up. It is possible for a clinical psychologist to use weekly support, or support on demand with expected equal clinical effects, but at the risk of treatment satisfaction and number of modules accesses during treatment.

\section{Limitations}

There are limitations that should be considered when interpreting the results presented in this thesis. All four studies contain a majority of female participants, on average $83 \%$. Even if the diagnosis is roughly twice as common in females, the sample can be viewed as somewhat unrepresentative in gender distribution. Studies II-IV included participants recruited in a community sample. The sample was highly educated, and the majority were either working or studying, indicating that the sample might contain resourceful individuals. Furthermore, the participants were probably highly motivated since they had sought the treatment themselves. At the same time, the results from the studies are similar to the effects in studies in clinical settings (Hobbs et al., 2017; Mewton et al., 2012). In study II, $25 \%$ had a current comorbid depressive disorder. In study IV, a majority (65.9\%) had one or more current comorbid diagnoses and $68.2 \%$ had a history of depressive disorders. A large proportion in the studies also had previous experiences of psychotherapy and of medication. Together, this indicates that even though they are highly educated, it is a sample that is somewhat representative of a GAD patient seen in primary or specialist care. 
Studies I and III were small pilot trials without a control group. However, in study I, none of the participants had sought internet-based treatment, and all were regular patients in primary care. The criteria for exclusion was few giving the study external validity to some degree. Study III included three measure points, at inclusion to study II (the RCT in which the participants in study III were randomized to waitinglist condition), pre-treatment, and post-treatment. With this design, the effects from nine weeks of being in a control condition could be compared with the effects from nine weeks of treatment. Even if the group did make significant improvements during the nine weeks of waiting for treatment, significant effects were observed after treatment compared with pre-treatment scores.

Only two of the studies included follow-ups. Study I included a threemonth follow-up and study II a six-month follow-up. Even if the results from these studies indicates that the effects post-treatment were maintained or continued to improve until follow-up, a longer follow-up is necessary to provide a clearer picture of the effects from the treatment. Perhaps this is particularly important with a population suffering from GAD, which is a disorder with a fluctuating character and a high rate of relapse, even if research indicates that treatment effects are maintained to a large extent (Cuijpers et al., 2014).

Study IV used a factorial design with four different treatment groups. Due to the lack of staff and the timeframe the study was unfortunately not sufficiently powered to detect small differences. As a result, the investigation of effects other than the main effects, were limited. Even if the results were not statistically significant, a tendency in the data was that Oroshjälpen and weekly support had larger effects sizes. Oroshjälpen also had significantly more participants not meeting GAD criteria at post-treatment. If more participants had been included, it is possible that the tentative differences would emerge or disappear, and more definite interpretations could be made. 
In all four studies, people involved in the research performed the diagnostic interviews. It is possible that interpretations of answers during the interviews were affected by this. The optimal way would have been to use independent researchers to collect this type of data, or listen to recordings of the interviews, as there can be situations that answers must be interpreted by the person doing the interview. The intake interviews for studies II-IV were presented and evaluated in referral meetings with experienced psychologists and researchers as a way to address this concern, but no such meetings were held regarding the post-treatment interviews.

\section{Ethical considerations}

When conducting and interpreting research, it is important to consider the context of the research. In the case of the studies included in this thesis, I am the main author of all articles and have been a part of the design and execution of all studies to some degree. I have done so in my role as a researcher. At the same time, I am employed at the private company Psykologpartners that owns Oroshjälpen. The program was developed by myself and other psychologist working at the private company. As a way to handle this, all data have been collected by the students or psychologists involved in the studies. Calculations have been done in collaboration with other authors of the articles and my supervisors as a $\mathrm{PhD}$ student, which have no connection to the private company. Furthermore, the studies have been conducted at university setting with no direct influence from the company itself and with the understanding that the results would be published no matter what they indicated. 


\section{Future directions}

Future research investigating the effects of the treatment program could broaden the application of the treatment to different formats and settings. A study in clinical settings could provide valuable information of the effects from treatment with regular patients, and support provided from staff in regular care. There are studies indicating that ICBT for GAD can be implemented in routine care with positive outcomes (Hobbs et al., 2017). However, the effects might be somewhat smaller and with higher rates of non-completers (Mewton et al., 2012), and not all studies report maintained effects (Richards et al., 2016). Study I, was a small pilot trial in a clinical setting with patients not seeking internet-based treatments, providing initial positive indications. However, it was a small trial and a large-scale study with an active comparison would provide valuable information about the effectiveness of the treatment.

To my knowledge, no study comparing face-to-face treatment and internet-based treatment for GAD has been published. A study comparing Oroshjälpen delivered online with delivery face-to-face could provide information regarding the effects of the two modes of delivery and the content of the treatment. A study by Lappalainen et al (2014) comparing internet-based ACT for depression with the same treatment delivered in a group setting reported differences in patterns of change. Significantly greater effects on depressive symptoms, general health and quality of life in favour of iACT were reported at post-treatment and at six-month follow-up, and for depressive symptoms at 18 months follow-up.

There are several possible areas for further research and development regarding the treatment program in itself. Future developments of the program could address the weaker effects on quality of life. One of the key principles in ACT/ABBT, as well as in Oroshjälpen, is helping the patient engage in meaningful activities as an opposite to entanglement 
in worry and experiential avoidance. A possible development of the program could be to expand the values work which is done early in treatment. The behavioural exercises addressing engagement in valued actions might need to be further developed. However, in a study examining change mechanisms in ABBT for GAD, increased engagement in meaningful activities and change in worry did not predict quality of life (Hayes, Orsillo, \& Roemer, 2010), but change in acceptance did. This indicates that further developments of the treatment might also benefit from expanding the acceptance work, as a way to address the smaller effects in life quality. At the same time, it is possible that the quality of life measures included in the studies do not correspond well with how the patients rate quality of life or what influence an internet-based treatment can have on the experiences of life quality.

The program was designed to be user-friendly and incorporate animations and video material instead of being only text-based. Whether this actually makes a positive impact on program usage or outcomes has not been evaluated other than ratings of how the program was perceived in study III. A possible way to address these questions could be to compare the treatment material delivered in two different formats and collect data on user friendliness in connection to adherence and outcomes. Furthermore, with the help of smartphone technology further adaptations could be made. A recent study by Carl et al. (2020) investigated a smartphone application for GAD with positive effects. By transforming the treatment to a smartphone application, it can be made more accessible. By doing so, teaching and training skills, as well as keeping records can be integrated in everyday life in ways the treatment program cannot be today.

Trough dismantling studies, or further factorial trials, the relative contribution of different modules could be examined and inform further developments of the program. By manipulating the order of modules, or exclude modules in different groups, it would be possible 
to investigate the impact of different modules and interaction effects between them. Another aspect that could be incorporated in a similar study design is the timeframe of delivery. The timeframe of internetbased treatment studies is often constricted by practical issues, or based on the assumption that one module per week is an appropriate time, following a traditional time frame in face-to-face treatment with appointments each week. However, recurring feedback in treatment studies following this timeframe are experiences of lack of time and participants feeling stressed (Hadjistavropoulos, Alberts, Nugent, \& Marchildon, 2014; Johansson et al., 2015). In study I, the participants were allowed to continue until they had gone through the whole treatment, resulting in an average treatment time of 15 weeks, which is considerably more than the eight or nine weeks in the other studies. A longer timeframe for completion corresponds with my personal experience from delivering face-to-face treatments and internet-based treatments in regular care and giving patients a choice of when they want to have the next session. However, a study on therapist behaviour in ICBT for GAD showed that deadline flexibility had a negative impact on outcome (Paxling et al., 2013), indicating that even if the program is delivered during a longer period of time, it might be important to have continued deadlines thought the treatment. By manipulating the timeframe to a larger extent in future studies it is possible that important information about delivery and its effects on adherence, treatment satisfaction, and clinical outcomes can be found.

Even if support type did not show significant effects on outcomes in the studies, it had an effect on treatment satisfaction and adherence. Studies indicate that there might be different patterns of change between responders and non-responders (Sunderland et al., 2012). Further studies investigating the impact of support could match support to preferences as well as well as adapting support for those at risk for not responding or reporting negative effects. Even if support on demand might be preferred by a patient it is possible that the support must be more pro-active and change to a more intense form if a patient 
is at risk of not responding to treatment. In an interesting study by (Forsell et al., 2019), an adapted ICBT treatment with more support or change in treatment material was given for participants identified as being at risk of treatment failure. Further investigations of this form of monitoring and adapting support or treatment material might be a promising approach to delivery of support, rather than choosing one or the other.

Another possible area of research and adaptation of treatments could be further development and applications of booster sessions or relapse prevention programs that are initiated after treatment. A study by Holländare et al. (2013) indicated that receiving an ICBT relapseprevention program after psychotherapy or medical treatment for depression had positive effects at follow-up two years after treatment. Furthermore, a study on mindfulness practice after receiving ABBT for GAD indicated that continued use of mindfulness had a significant effect on continued improvement in worry, anxiety and quality of life (Morgan, Graham, Hayes-Skelton, Orsillo, \& Roemer, 2014). Relapseprevention and continued work with the skills learned are often addressed in the last modules in ICBT. A flexible relapse prevention program that are delivered no matter how many modules accessed during treatment could be a way to address maintenance of the skills learned for those not accessing all modules during treatment.

On a more general note, as a clinical psychologist I often wonder how important change in symptoms is, and how change in symptoms correspond with changes in everyday life functioning and well-being. In study IV a significant effect was seen on self-efficacy which is interesting. An important aspect of all psychological treatment is to help the patient develop a sense of competency to handle difficulties in life. But what does this effect on self-efficacy mean in terms of behaviour change in everyday life for the patient. Future studies could include other types of evaluations besides symptoms and diagnostic measures to address this. By using ratings of perceived disability or 
functioning in different areas, and rates of behavioural change, the impact of treatment on everyday concerns could be evaluated and possibly guide further developments of the program.

Finally, treating GAD patients with evidence-based manuals often is viewed as difficult in several ways by the clinician. One of the strengths with internet-based treatments is that they are highly structured, both for the patient and the clinician delivering support. It is possible that in the future, internet-based treatments for GAD could be an important tool in developing and testing new treatments in large scale settings, then transforming them into face-to-face manuals, opposite from the situation today. Internet-based treatments also could be a vital part of educating and training clinicians. By training clinicians in the delivery of internet-based treatments, they can learn new treatment strategies, as well as getting the experience of conducting manualized treatments that are effective while controlling for therapist drift (Waller \& Turner, 2016). 


\section{Conclusion}

From a clinical perspective, internet-based treatments have many strengths. The treatment is accessible at all times and do not require extensive therapist time. Furthermore, the programs are highly structured, helping both the clinician and the patient to focus on the work that needs to be done, and guide them through methods that have been shown to be effective. This thesis included some of the first published studies on internet-based treatment for GAD based on an acceptance-based approach. The treatment had three guiding principles; acceptance, mindfulness, and valued action that were presented as an alternative to responding with worry and avoidance when negative experiences occur. The results indicate that the treatment was effective in reducing worry, GAD related symptoms, as well as comorbid symptoms. Furthermore, treatment can be delivered with weekly support or support on demand with similar effects on treatment outcomes. It is my hope that the program developed and tested in this thesis can help both patients and clinicians to not get tangled in experiential avoidance during treatment or in life. 


\section{References}

A-Tjak, J., Davis, M., Morina, N., Powers, M., Smits, J., \& Emmelkamp, P. (2015). A meta-analysis of the efficacy of acceptance and commitment therapy for clinically relevant mental and physical health problems. Psychotherapy and Psychosomatics, 84(1), 30-36. doi:10.1159/000365764

Allgulander, C. (2012). Generalized anxiety disorder: a review of recent findings. Journal of Experimental \& Clinical Medicine, 4(2), 88-91. doi:doi.org/10.1016/j.jecm.2012.01.006

American Psychiatric Association. (2013). Desk reference to the diagnostic criteria from DSM-5: American Psychiatric Association.

Andersson, E., Hedman, E., Wadström, O., Boberg, J., Andersson, E. Y., Axelsson, E., . . . Ljótsson, B. (2017). Internet-based extinction therapy for worry: a randomized controlled trial. Behavior Therapy, 48(3), 391-402. doi:doi.org/10.1016/j.beth.2016.07.003

Andersson, E., Ljotsson, B., Hedman-Lagerlof, M., Nygren, L., Persson, M., Rosengren, K., . . . Hedman-Lagerlof, E. (2020). Targeting excessive worry with internet-based extinction therapy: a randomised controlled trial with mediation analysis and economical evaluation. Psychological Medicine, 1-11. doi:10.1017/S0033291720000781

Andersson, G. (2015). The internet and CBT : a clinical guide: CRC Press.

Andersson, G. (2018). Internet interventions: Past, present and future. Internet Interventions, 12, 181-188. doi:10.1016/j.invent.2018.03.008

Andersson, G., Carlbring, P., \& Rozental, A. (2019). Response and remission rates in internet-based cognitive behavior therapy: an individual patient data meta-analysis. Frontiers in psychiatry, 10, 749. doi:doi.org/10.3389/fpsyt.2019.00749

Andersson, G., Estling, F., Jakobsson, E., Cuijpers, P., \& Carlbring, P. (2011). Can the patient decide which modules to endorse? An open trial of tailored internet treatment of anxiety disorders. Cognitive Behaviour Therapy, 40(1), 57-64. doi:10.1080/16506073.2010.529457

Andersson, G., Paxling, B., Roch-Norlund, P., Östman, G., Norgren, A., Almlöv, J., . . . Silverberg, F. (2012). Internet-based psychodynamic versus cognitive behavioral guided self-help for generalized anxiety disorder: a randomized controlled trial. Psychotherapy and Psychosomatics, 81(6), 344-355. doi:doi.org/10.1159/000339371

Andersson, G., Paxling, B., Wiwe, M., Vernmark, K., Felix, C. B., Lundborg, L., . . Carlbring, P. (2012). Therapeutic alliance in guided internet- 
delivered cognitive behavioural treatment of depression, generalized anxiety disorder and social anxiety disorder. Behaviour Research and Therapy, 50(9), 544-550. doi:10.1016/j.brat.2012.05.003

Andersson, G., Rozental, A., Shafran, R., \& Carlbring, P. (2018). Long-term effects of internet-supported cognitive behaviour therapy. Expert Review of Neurotherapeutics, 18(1), 21-28. doi:10.1080/14737175.2018.1400381

Andersson, G., \& Titov, N. (2014). Advantages and limitations of Internetbased interventions for common mental disorders. World psychiatry : official journal of the World Psychiatric Association (WPA), 13(1), 4-11. doi:10.1002/wps.20083

Andrews, G., Basu, A., Cuijpers, P., Craske, M. G., McEvoy, P., English, C. L., \& Newby, J. M. (2018). Computer therapy for the anxiety and depression disorders is effective, acceptable and practical health care: An updated meta-analysis. Journal of Anxiety Disorders, 55, 70-78. doi:10.1016/j.janxdis.2018.01.001

Arntz, A. (2003). Cognitive therapy versus applied relaxation as treatment of generalized anxiety disorder. Behaviour Research and Therapy, 41(6), 633-646. doi:10.1016/s0005-7967(02)00045-1

Avdagic, E., Morrissey, S. A., \& Boschen, M. J. (2014). A randomised controlled trial of acceptance and commitment therapy and cognitivebehaviour therapy for generalised anxiety disorder. Behaviour Change, 31(2), 110-130. doi:10.1017/bec.2014.5

Barlow, D. H. (2002). Anxiety and its disorders : the nature and treatment of anxiety and panic (2. ed. ed.): Guilford Publications.

Baumeister, H., Reichler, L., Munzinger, M., \& Lin, J. (2014). The impact of guidance on Internet-based mental health interventions - a systematic review. Internet Interventions, 1(4), 205-215. doi:doi.org/10.1016/j.invent.2014.08.003

Beesdo, K., Hoyer, J., Jacobi, F., Low, N. C. P., Höfler, M., \& Wittchen, H.U. (2009). Association between generalized anxiety levels and pain in a community sample: Evidence for diagnostic specificity. Journal of Anxiety Disorders, 23(5), 684-693. doi:doi.org/10.1016/j.janxdis.2009.02.007

Beesdo, K., Pine, D. S., Lieb, R., \& Wittchen, H.-U. (2010). Incidence and risk patterns of anxiety and depressive disorders and categorization of generalized anxiety disorder. Archives of general psychiatry, 67(1), 47-57.

Behar, E., Alcaine, O., Zuellig, A. R., \& Borkovec, T. D. (2003). Screening for generalized anxiety disorder using the Penn State Worry Questionnaire: A receiver operating characteristic analysis. J Behav 
Ther Exp Psychiatry, 34(1), 25-43. doi:10.1016/s00057916(03)00004-1

Behar, E., DiMarco, I. D., Hekler, E. B., Mohlman, J., \& Staples, A. M. (2009). Current theoretical models of generalized anxiety disorder (GAD): Conceptual review and treatment implications. Journal of Anxiety Disorders, 23(8), 1011-1023. doi:doi.org/10.1016/j.janxdis.2009.07.006

Bobes, J., Caballero, L., Vilardaga, I., \& Rejas, J. (2011). Disability and health-related quality of life in outpatients with generalised anxiety disorder treated in psychiatric clinics: Is there still room for improvement? Annals of General Psychiatry, 10(1), 7. doi:10.1186/1744-859X-10-7

Bond, F. W., Hayes, S. C., Baer, R. A., Carpenter, K. M., Guenole, N., Orcutt, H. K., . . Zettle, R. D. (2011). Preliminary psychometric properties of the Acceptance and Action Questionnaire-II: A revised measure of psychological inflexibility and experiential avoidance. Behavior Therapy, 42(4), 676-688. doi:10.1016/j.beth.2011.03.007

Borkovec, T. D., Alcaine, O. M., \& Behar, E. (2004). Avoidance theory of worry and generalized anxiety disorder. In Generalized anxiety disorder: Advances in research and practice. (pp. 77-108). New York, NY, US: The Guilford Press.

Borkovec, T. D., \& Costello, E. (1993). Efficacy of applied relaxation and cognitive-behavioral therapy in the treatment of generalized anxiety disorder. Journal of Consulting and Clinical Psychology, 61(4), 611619. doi:doi.org/10.1037//0022-006x.61.4.611

Borkovec, T. D., Newman, M. G., Pincus, A. L., \& Lytle, R. (2002). A component analysis of cognitive-behavioral therapy for generalized anxiety disorder and the role of interpersonal problems. Journal of Consulting and Clinical Psychology, 70(2), 288-298. doi:doi.org/10.1037/0022-006X.70.2.288

Borkovec, T. D., \& Roemer, L. (1995). Perceived functions of worry among generalized anxiety disorder subjects: distraction from more emotionally distressing topics? J Behav Ther Exp Psychiatry, 26(1), 25-30. doi:doi.org/10.1016/0005-7916(94)00064-s

Buhrman, M., Skoglund, A., Husell, J., Bergström, K., Gordh, T., Hursti, T., . . . Andersson, G. (2013). Guided internet-delivered acceptance and commitment therapy for chronic pain patients: A randomized controlled trial. Behaviour Research and Therapy, 51(6), 307-315. doi:10.1016/j.brat.2013.02.010

Burke, J., Richards, D., \& Timulak, L. (2019). Helpful and hindering events in internet-delivered cognitive behavioural treatment for generalized 
anxiety. Behavioural and Cognitive Psychotherapy, 47(3), 386-399. doi:10.1017/s1352465818000504

Carl, E., Witcraft, S. M., Kauffman, B. Y., Gillespie, E. M., Becker, E. S., Cuijpers, P., . . . Powers, M. B. (2020). Psychological and pharmacological treatments for generalized anxiety disorder (GAD): A meta-analysis of randomized controlled trials. Cognitive Behaviour Therapy, 49(1), 1-21. doi:doi.org/10.1080/16506073.2018.1560358

Carl, J. R., Miller, C. B., Henry, A. L., Davis, M. L., Stott, R., Smits, J. A. J., . . . Espie, C. A. (2020). Efficacy of digital cognitive behavioral therapy for moderate-to-severe symptoms of generalized anxiety disorder: A randomized controlled trial. Depression And Anxiety, $n / a(n / a)$. doi:10.1002/da.23079

Carlbring, P., Andersson, G., Cuijpers, P., Riper, H., \& Hedman-Lagerlof, E. (2018). Internet-based vs. face-to-face cognitive behavior therapy for psychiatric and somatic disorders: an updated systematic review and meta-analysis. Cognitive Behaviour Therapy, 47(1), 1-18. doi:10.1080/16506073.2017.1401115

Carlbring, P., Maurin, L., Törngren, C., Linna, E., Eriksson, T., Sparthan, E., . . . Andersson, G. (2011). Individually-tailored, Internet-based treatment for anxiety disorders: A randomized controlled trial. Behaviour Research and Therapy, 49(1), 18-24. doi:10.1016/j.brat.2010.10.002

Carpenter, J. K., Andrews, L. A., Witcraft, S. M., Powers, M. B., Smits, J. A. J., \& Hofmann, S. G. (2018). Cognitive behavioral therapy for anxiety and related disorders: A meta-analysis of randomized placebo-controlled trials. Depression And Anxiety, 35(6), 502-514. doi:doi.org/10.1002/da.22728

Cerda, M., Sagdeo, A., Johnson, J., \& Galea, S. (2010). Genetic and environmental influences on psychiatric comorbidity: A systematic review. Journal of Affective Disorders, 126(1-2), 14-38. doi:doi.org/10.1016/j.jad.2009.11.006

Cougle, J. R., Fitch, K. E., Fincham, F. D., Riccardi, C. J., Keough, M. E., \& Timpano, K. R. (2012). Excessive reassurance seeking and anxiety pathology: tests of incremental associations and directionality. Journal of Anxiety Disorders, 26(1), 117-125. doi:doi.org/10.1016/j.janxdis.2011.10.001

Crocq, M. A. (2017). The history of generalized anxiety disorder as a diagnostic category. Dialogues in clinical neuroscience, 19(2), 107116.

Cuijpers, P., Sijbrandij, M., Koole, S., Huibers, M., Berking, M., \& Andersson, G. (2014). Psychological treatment of generalized 
anxiety disorder: A meta-analysis. Clinical Psychology Review, 34(2), 130-140. doi:doi.org/10.1016/j.cpr.2014.01.002

Dear, B. F., Staples, L. G., Terides, M. D., Karin, E., Zou, J., Johnston, L., . . . Titov, N. (2015). Transdiagnostic versus disorder-specific and clinician-guided versus self-guided internet-delivered treatment for generalized anxiety disorder and comorbid disorders: A randomized controlled trial. Journal of Anxiety Disorders, 36, 63-77. doi:doi.org/10.1016/j.janxdis.2015.09.003

Dugas, M. J., Brillon, P., Savard, P., Turcotte, J., Gaudet, A., Ladouceur, R., . . . Gervais, N. J. (2010). A randomized clinical trial of cognitivebehavioral therapy and applied relaxation for adults with generalized anxiety disorder. Behavior Therapy, 41(1), 46-58. doi:10.1016/j.beth.2008.12.004

Dugas, M. J., Freeston, M. H., Ladouceur, R., Rhéaume, J., Provencher, M., \& Boisvert, J.-M. (1998). Worry themes in primary GAD, secondary GAD, and other anxiety disorders. Journal of Anxiety Disorders, 12(3), 253-261. doi:doi.org/10.1016/S0887-6185(98)00013-9

Dugas, M. J., Gagnon, F., Ladouceur, R., \& Freeston, M. H. (1998). Generalized anxiety disorder: a preliminary test of a conceptual model. Behaviour Research and Therapy, 36(2), 215-226. doi:doi.org/10.1016/s0005-7967(97)00070-3

Dupuy, J. B., Beaudoin, S., Rheaume, J., Ladouceur, R., \& Dugas, M. J. (2001). Worry: daily self-report in clinical and non-clinical populations. Behaviour Research and Therapy, 39(10), 1249-1255. doi:doi.org/10.1016/s0005-7967(01)00011-0

Fisher, P. L. (2006). The efficacy of psychological treatments for generalised anxiety disorder? In Worry and its Psychological Disorders (pp. 359377).

Foa, E. B., \& Kozak, M. J. (1986). Emotional processing of fear: Exposure to corrective information. Psychological Bulletin, 99(1), 20-35. doi:10.1037/0033-2909.99.1.20

Forsell, E., Jernelöv, S., Blom, K., Kraepelien, M., Svanborg, C., Andersson, G., . . . Kaldo, V. (2019). Proof of concept for an adaptive treatment strategy to prevent failures in internet-delivered CBT: a single-blind randomized clinical trial with insomnia patients. American Journal of Psychiatry, 176(4), 315-323. doi:10.1176/appi.ajp.2018.18060699

French, K., Golijani-Moghaddam, N., \& Schröder, T. (2017). What is the evidence for the efficacy of self-help acceptance and commitment therapy? A systematic review and meta-analysis. Journal of contextual behavioral science, 6(4), 360-374. doi:doi.org/10.1016/j.jcbs.2017.08.002 
Frisch, M. B., Cornell, J., Villanueva, M., \& Retzlaff, P. J. (1992). Clinical validation of the Quality of Life Inventory. A measure of life satisfaction for use in treatment planning and outcome assessment. Psychological Assessment, 4(1), 92-101. doi:10.1037/10403590.4.1.92

Gersh, E., Hallford, D. J., Rice, S. M., Kazantzis, N., Gersh, H., Gersh, B., \& McCarty, C. A. (2017). Systematic review and meta-analysis of dropout rates in individual psychotherapy for generalized anxiety disorder. Journal of Anxiety Disorders, 52, 25-33. doi:doi.org/10.1016/j.janxdis.2017.10.001

Gillis, M. M., Haaga, D. A. F., \& Ford, G. T. (1995). Normative values for the Beck Anxiety Inventory, Fear Questionnaire, Penn State Worry Questionnaire, and Social Phobia and Anxiety Inventory. Psychological Assessment, 7(4), 450-455. doi:10.1037/10403590.7.4.450

Goodwin, H., Yiend, J., \& Hirsch, C. R. (2017). Generalized anxiety disorder, worry and attention to threat: A systematic review. Clinical Psychology Review, 54, 107-122. doi:doi.org/10.1016/j.cpr.2017.03.006

Gottschalk, M. G., \& Domschke, K. (2017). Genetics of generalized anxiety disorder and related traits. Dialogues in clinical neuroscience, 19(2), 159-168.

Grant, B. F., Hasin, D. S., Stinson, F. S., Dawson, D. A., June Ruan, W., Goldstein, R. B., . . . Huang, B. (2005). Prevalence, correlates, comorbidity, and comparative disability of DSM-IV generalized anxiety disorder in the USA: Results from the National Epidemiologic Survey on Alcohol and Related Conditions. Psychological Medicine, 35(12), 1747-1759. doi:doi.org/10.1017/S0033291705006069

Guy, W. (1976). Clinical Global Impression, ECDEU Assessment Manual for Psychopharmacology, Revised. National Institute of Mental Health, Rockville.

Hadjistavropoulos, H. D., Alberts, N. M., Nugent, M., \& Marchildon, G. (2014). Improving access to psychological services through therapistassisted, internet-delivered cognitive behaviour therapy. Canadian Psychology, 55, 303-311.

Hadjistavropoulos, H. D., Pugh, N., Hesser, H., \& Andersson, G. (2017). Therapeutic alliance in internet-delivered cognitive behaviour therapy for depression or generalized anxiety. Clinical Psychology \& Psychotherapy, 24(2), 451-461. doi:doi.org/10.1002/cpp.2014

Hadjistavropoulos, H. D., Schneider, L. H., Edmonds, M., Karin, E., Nugent, M. N., Dirkse, D., . . Titov, N. (2017). Randomized controlled trial 
of internet-delivered cognitive behaviour therapy comparing standard weekly versus optional weekly therapist support. Journal of Anxiety Disorders, 52, 15-24. doi:doi.org/10.1016/j.janxdis.2017.09.006

Hadjistavropoulos, H. D., Schneider, L. H., Mehta, S., Karin, E., Dear, B. F., \& Titov, N. (2019). Preference trial of internet-delivered cognitive behaviour therapy comparing standard weekly versus optional weekly therapist support. Journal of Anxiety Disorders, 63, 51-60. doi:doi.org/10.1016/j.janxdis.2019.02.002

Haller, H., Cramer, H., Lauche, R., Gass, F., \& Dobos, G. J. (2014). The prevalence and burden of subthreshold generalized anxiety disorder: a systematic review. BMC Psychiatry, 14, 128. doi:10.1186/1471$244 \mathrm{x}-14-128$

Hayes, S. A., Orsillo, S. M., \& Roemer, L. (2010). Changes in proposed mechanisms of action during an acceptance-based behavior therapy for generalized anxiety disorder. Behaviour Research and Therapy, 48(3), 238-245. doi:doi.org/10.1016/j.brat.2009.11.006

Hayes, S. C., \& Hofmann, S. G. (2017). The third wave of cognitive behavioral therapy and the rise of process-based care. World psychiatry: Official Journal of the World Psychiatric Association (WPA), 16(3), 245-246. doi:10.1002/wps.20442

Hayes, S. C., Strosahl, K. D., \& Wilson, K. G. (1999). Acceptance and commitment therapy : an experiential approach to behavior change: Guilford Press.

Hayes-Skelton, S. A., Orsillo, S. M., \& Roemer, L. (2013). An acceptancebased behavioral therapy for individuals with generalized anxiety disorder. Cognitive and behavioral practice, 20(3), 264-281. doi:doi.org/10.1016/j.cbpra.2011.02.005

Hayes-Skelton, S. A., Roemer, L., \& Orsillo, S. M. (2013). A randomized clinical trial comparing an acceptance-based behavior therapy to applied relaxation for generalized anxiety disorder. Journal of Consulting and Clinical Psychology, 81(5), 761-773. doi:doi.org/10.1037/a0032871

Heimberg, R. G., Turk, C. L., \& Mennin, D. S. (2004). Generalized anxiety disorder : advances in research and practice: New York : Guilford Press, 2004.

Hesser, H., Gustafsson, T., Lunden, C., Henrikson, O., Fattahi, K., Johnsson, E., . . . Andersson, G. (2012). A randomized controlled trial of internet-delivered cognitive behavior therapy and acceptance and commitment therapy in the treatment of tinnitus. Journal of Consulting and Clinical Psychology, 80(4), 649-661. doi:10.1037/a0027021 
Hettema, J. M., Neale, M. C., Myers, J. M., Prescott, C. A., \& Kendler, K. S. (2006). A population-based twin study of the relationship between neuroticism and internalizing disorders. The American journal of psychiatry, 163(5), 857-864. doi:doi.org/10.1176/ajp.2006.163.5.857

Hilbert, K., Lueken, U., \& Beesdo-Baum, K. (2014). Neural structures, functioning and connectivity in Generalized Anxiety Disorder and interaction with neuroendocrine systems: a systematic review. Journal of Affective Disorders, 158, 114-126. doi:10.1016/j.jad.2014.01.022

Hirsch, C. R., \& Mathews, A. (2012). A cognitive model of pathological worry. Behaviour Research and Therapy, 50(10), 636-646. doi:doi.org/10.1016/j.brat.2012.06.007

Hirsch, C. R., Mathews, A., Lequertier, B., Perman, G., \& Hayes, S. (2013). Characteristics of worry in generalized anxiety disorder. J Behav Ther Exp Psychiatry, 44(4), 388-395. doi:doi.org/10.1016/j.jbtep.2013.03.004

Hobbs, M. J., Mahoney, A. E. J., \& Andrews, G. (2017). Integrating iCBT for generalized anxiety disorder into routine clinical care: Treatment effects across the adult lifespan. Journal of Anxiety Disorders, 51, 47-54. doi:doi.org/10.1016/j.janxdis.2017.09.003

Hoffman, D. L., Dukes, E. M., \& Wittchen, H.-U. (2008). Human and economic burden of generalized anxiety disorder. Depression And Anxiety, 25(1), 72-90. doi:doi.org/10.1002/da.20257

Hofmann, S. G., Wu, J. Q., \& Boettcher, H. (2014). Effect of cognitivebehavioral therapy for anxiety disorders on quality of life: A metaanalysis. Journal of Consulting and Clinical Psychology, 82(3), 375391. doi:doi.org/10.1037/a0035491

Hollandare, F., Anthony, S. A., Randestad, M., Tillfors, M., Carlbring, P., Andersson, G., \& Engstrom, I. (2013). Two-year outcome of internet-based relapse prevention for partially remitted depression. Behaviour Research and Therapy, 51(11), 719-722. doi:10.1016/j.brat.2013.08.002

Jacobson, N. S., \& Truax, P. (1991). Clinical significance: a statistical approach to defining meaningful change in psychotherapy research. Journal of Consulting and Clinical Psychology, 59(1), 12-19. doi:10.1037//0022-006x.59.1.12

Johansson, O., Michel, T., Andersson, G., \& Paxling, B. (2015). Experiences of non-adherence to Internet-delivered cognitive behavior therapy: A qualitative study. Internet Interventions, 2(2), 137-142. doi:doi.org/10.1016/j.invent.2015.02.006

Johansson, R., Carlbring, P., Heedman, A., Paxling, B., \& Andersson, G. (2013). Depression, anxiety and their comorbidity in the Swedish 
general population: point prevalence and the effect on health-related quality of life. PeerJ, 1, e98. doi:10.7717/peerj.98

Johnston, L., Titov, N., Andrews, G., Spence, J., \& Dear, B. F. (2011). A RCT of a transdiagnostic internet-delivered treatment for three anxiety disorders: examination of support roles and disorder-specific outcomes. Plos One, 6(11), e28079-e28079. doi:10.1371/journal.pone.0028079

Kelson, J., Rollin, A., Ridout, B., \& Campbell, A. (2019). Internet-delivered acceptance and commitment therapy for anxiety treatment: systematic review. Journal of Medical Internet Research, 21(1), e12530. doi:10.2196/12530

Kertz, S., \& Woodruff-Borden, J. (2011). Human and Economic Burden of GAD, Subthreshold GAD, and worry in a primary care sample. Journal of Clinical Psychology in Medical Settings, 18(3), 281. doi:doi.org/10.1007/s10880-011-9248-1

Kessler, R. C., Petukhova, M., Sampson, N. A., Zaslavsky, A. M., \& Wittchen, H.-U. (2012). Twelve-month and lifetime prevalence and lifetime morbid risk of anxiety and mood disorders in the United States. International journal of methods in psychiatric research, 21(3), 169-184. doi:doi.org/10.1002/mpr.1359

Kroenke, K., Spitzer, R. L., \& Williams, J. B. (2001). The PHQ-9: Validity of a brief depression severity measure. J Gen Intern Med, 16(9), 606613. doi:10.1046/j.1525-1497.2001.016009606.x

Ladouceur, R., Blais, F., Freeston, M. H., \& Dugas, M. J. (1998). Problem solving and problem orientation in generalized anxiety disorder. Journal of Anxiety Disorders, 12(2), 139-152. doi:doi.org/10.1016/S0887-6185(98)00002-4

LaFreniere, L. S., \& Newman, M. G. (2020). Exposing Worry's Deceit: Percentage of Untrue Worries in Generalized Anxiety Disorder Treatment. Behavior Therapy, 51(3), 413-423.

Lappalainen, P., Granlund, A., Siltanen, S., Ahonen, S., Vitikainen, M., Tolvanen, A., \& Lappalainen, R. (2014). ACT Internet-based vs face-to-face? A randomized controlled trial of two ways to deliver Acceptance and Commitment Therapy for depressive symptoms: an 18-month follow-up. Behaviour Research and Therapy, 61, 43-54. doi:10.1016/j.brat.2014.07.006

Lappalainen, P., Langrial, S., Oinas-Kukkonen, H., Muotka, J., \& Lappalainen, R. (2019). ACT for sleep - internet-delivered self-help ACT for sub-clinical and clinical insomnia: a randomized controlled trial. Journal of contextual behavioral science, 12, 119-127. doi:doi.org/10.1016/j.jcbs.2019.04.001 
Lappalainen, P., Langrial, S., Oinas-Kukkonen, H., Tolvanen, A., \& Lappalainen, R. (2015). Web-based acceptance and commitment therapy for depressive symptoms with minimal support: a randomized controlled trial. Behavior Modification, 39(6), 805-834. doi: $10.1177 / 0145445515598142$

Larsen, D. L., Attkisson, C. C., Hargreaves, W. A., \& Nguyen, T. D. (1979). Assessment of client/patient satisfaction: Development of a general scale. Evaluation and Program Planning, 2(3), 197-207. doi:doi.org/10.1016/0149-7189(79)90094-6

Legerstee, J. S., Garnefski, N., Verhulst, F. C., \& Utens, E. M. W. J. (2011). Cognitive coping in anxiety-disordered adolescents. Journal of adolescence, $34(2)$,

319-326. doi:doi.org/10.1016/j.adolescence.2010.04.008

Lindner, P., Andersson, G., Öst, L.-G., \& Carlbring, P. (2013). Validation of the internet-administered quality of life inventory (QOLI) in different psychiatric conditions. Cognitive Behaviour Therapy, 42(4), 315327. doi:10.1080/16506073.2013.806584

Lindner, P., Frykheden, O., Forsström, D., Andersson, E., Ljótsson, B., Hedman, E., . . . Carlbring, P. (2016). The Brunnsviken Brief Quality of Life Scale (BBQ): development and psychometric evaluation. Cognitive Behaviour Therapy, 45(3), 182-195. doi:10.1080/16506073.2016.1143526

Loerinc, A. G., Meuret, A. E., Twohig, M. P., Rosenfield, D., Bluett, E. J., \& Craske, M. G. (2015). Response rates for CBT for anxiety disorders: need for standardized criteria. Clinical Psychology Review, 42, 7282. doi:10.1016/j.cpr.2015.08.004

Löve, J., Moore, C. D., \& Hensing, G. (2012). Validation of the Swedish translation of the general self-efficacy scale. Quality of Life Research, 21(7), 1249-1253. doi:10.1007/s11136-011-0030-5

Mackintosh, M.-A., Gatz, M., Wetherell, J. L., \& Pedersen, N. L. (2006). A twin study of lifetime Generalized Anxiety Disorder (GAD) in older adults: genetic and environmental influences shared by neuroticism and GAD. Twin Research and Human Genetics: the Official Journal of the International Society for Twin Studies, 9(1), 30-37.

Marciniak, M. D., Lage, M. J., Dunayevich, E., Russell, J. M., Bowman, L., Landbloom, R. P., \& Levine, L. R. (2005). The cost of treating anxiety: the medical and demographic correlates that impact total medical costs. Depression And Anxiety, 21(4), 178-184. doi:doi.org/10.1002/da.20074

Martens, E. J., de Jonge, P., Na, B., Cohen, B. E., Lett, H., \& Whooley, M. A. (2010). Scared to death? Generalized anxiety disorder and cardiovascular events in patients with stable coronary heart disease: 
the heart and soul study. Archives of general psychiatry, 67(7), 750758. doi:10.1001/archgenpsychiatry.2010.74

Meier, S. M., Mattheisen, M., Mors, O., Mortensen, P. B., Laursen, T. M., \& Penninx, B. W. (2016). Increased mortality among people with anxiety disorders: total population study. The British Journal of Psychiatry: the Journal of Mental Science, 209(3), 216-221. doi:doi.org/10.1192/bjp.bp.115.171975

Mewton, L., Wong, N., \& Andrews, G. (2012). The effectiveness of internet cognitive behavioural therapy for generalized anxiety disorder in clinical practice. Depression And Anxiety, 29(10), 843-849. doi:10.1002/da.21995

Meyer, T. J., Miller, M. L., Metzger, R. L., \& Borkovec, T. D. (1990). Development and validation of the Penn State Worry Questionnaire. Behaviour Research and Therapy, 28(6), 487-495. doi:10.1016/00057967(90)90135-6

Montero-Marin, J., Garcia-Campayo, J., Lopez-Montoyo, A., Zabaleta-DelOlmo, E., \& Cuijpers, P. (2018). Is cognitive-behavioural therapy more effective than relaxation therapy in the treatment of anxiety disorders? A meta-analysis. Psychological Medicine, 48(9), 14271436. doi:10.1017/S0033291717003099

Moreno-Peral, P., Conejo-Ceron, S., Motrico, E., Rodriguez-Morejon, A., Fernandez, A., Garcia-Campayo, J., . . . Bellon, J. A. (2014). Risk factors for the onset of panic and generalised anxiety disorders in the general adult population: a systematic review of cohort studies. Journal of Affective Disorders, 168, 337-348. doi:doi.org/10.1016/j.jad.2014.06.021

Morgan, L. P. K., Graham, J. R., Hayes-Skelton, S. A., Orsillo, S. M., \& Roemer, L. (2014). Relationships between amount of postintervention of mindfulness practice and follow-up outcome variables in an acceptance-based behavior therapy for generalized anxiety disorder: the importance of informal practice. Journal of contextual behavioral science, 3(3), 173-176. doi:doi.org/10.1016/j.jcbs.2014.05.001

Mowrer, O. H. (1951). Two-factor learning theory: summary and comment. Psychol Rev, 58(5), 350-354. doi:10.1037/h0058956

Munk-Jørgensen, P., Allgulander, C., Dahl, A. A., Foldager, L., Holm, M., Rasmussen, 1., . . . Wittchen, H.-U. (2006). Prevalence of generalized anxiety disorder in general practice in Denmark, Finland, Norway, and Sweden. Psychiatric Services, 57(12), 1738-1744. doi:10.1176/appi.ps.57.12.1738

Nasiri, F., Mashhadi, A., Bigdeli, I., \& Chamanabad, A. G. (2020). How to differentiate generalized anxiety disorder from worry: the role of 
cognitive strategies. Journal of Rational-Emotive \& CognitiveBehavior Therapy, 38(1), 44-55. doi:10.1007/s10942-019-00323-5

Newman, M., Cho, S., \& Kim, H. (2016). Worry and Generalized Anxiety Disorder: A Review.

Newman, M. G., \& Llera, S. J. (2011). A novel theory of experiential avoidance in generalized anxiety disorder: a review and synthesis of research supporting a contrast avoidance model of worry. Clinical Psychology Review, 31(3), 371-382. doi:10.1016/j.cpr.2011.01.008

Newman, M. G., Llera, S. J., Erickson, T. M., Przeworski, A., \& Castonguay, L. G. (2013). Worry and generalized anxiety disorder: a review and theoretical synthesis of evidence on nature, etiology, mechanisms, and treatment. Annual review of clinical psychology, 9, 275-297. doi:doi.org/10.1146/annurev-clinpsy-050212-185544

Newman, M. G., Przeworski, A., Consoli, A. J., \& Taylor, C. B. (2014). A randomized controlled trial of ecological momentary intervention plus brief group therapy for generalized anxiety disorder. Psychotherapy (Chicago Ill.), 51(2), 198-206. doi:10.1037/a0032519

Newman, M. G., Przeworski, A., Fisher, A. J., \& Borkovec, T. D. (2010). Diagnostic comorbidity in adults with generalized anxiety disorder: impact of comorbidity on psychotherapy outcome and impact of psychotherapy on comorbid diagnoses. Behavior Therapy, 41(1), 5972. doi:10.1016/j.beth.2008.12.005

Newman, M. G., Zuellig, A. R., Kachin, K. E., Constantino, M. J., Przeworski, A., Erickson, T., \& Cashman-McGrath, L. (2002). Preliminary reliability and validity of the generalized anxiety disorder questionnaire-IV: A revised self-report diagnostic measure of generalized anxiety disorder. Behavior Therapy, 33(2), 215-233. doi:doi.org/10.1016/S0005-7894(02)80026-0

Nordahl, H. M., Borkovec, T. D., Hagen, R., Kennair, L. E. O., Hjemdal, O., Solem, S., . . . Wells, A. (2018). Metacognitive therapy versus cognitive-behavioural therapy in adults with generalised anxiety disorder. Bjpsych Open, 4(5), 393-400. doi:10.1192/bjo.2018.54

Nordgren, L. B., Hedman, E., Etienne, J., Bodin, J., Kadowaki, A., Eriksson, S., . . . Carlbring, P. (2014). Effectiveness and cost-effectiveness of individually tailored Internet-delivered cognitive behavior therapy for anxiety disorders in a primary care population: a randomized controlled trial. Behaviour Research and Therapy, 59, 1-11. doi:10.1016/j.brat.2014.05.007

Olatunji, B. O., Wolitzky-Taylor, K. B., Sawchuk, C. N., \& Ciesielski, B. G. (2010). Worry and the anxiety disorders: a meta-analytic synthesis of specificity to GAD. Applied and Preventive Psychology, 14(1-4), 124. doi:10.1016/j.appsy.2011.03.001 
Ost, L. G., \& Breitholtz, E. (2000). Applied relaxation vs. cognitive therapy in the treatment of generalized anxiety disorder. Behaviour Research and Therapy, 38(8), 777-790. doi:10.1016/s0005-7967(99)00095-9

Păsărelu, C. R., Andersson, G., Bergman Nordgren, L., \& Dobrean, A. (2017). Internet-delivered transdiagnostic and tailored cognitive behavioral therapy for anxiety and depression: a systematic review and meta-analysis of randomized controlled trials. Cognitive Behaviour Therapy, 46(1), 1-28. doi:10.1080/16506073.2016.1231219

Patriquin, M. A., \& Mathew, S. J. (2017). The neurobiological mechanisms of generalized anxiety disorder and chronic stress. Chronic stress (Thousand Oaks, Calif), 1. doi:doi.org/10.1177/2470547017703993

Paxling, B., Almlov, J., Dahlin, M., Carlbring, P., Breitholtz, E., Eriksson, T., \& Andersson, G. (2011). Guided internet-delivered cognitive behavior therapy for generalized anxiety disorder: a randomized controlled trial. Cognitive Behaviour Therrapy, 40(3), 159-173. doi:10.1080/16506073.2011.576699

Paxling, B., Lundgren, S., Norman, A., Almlov, J., Carlbring, P., Cuijpers, P., \& Andersson, G. (2013). Therapist behaviours in internetdelivered cognitive behaviour therapy: analyses of e-mail correspondence in the treatment of generalized anxiety disorder. Behavioural and Cognitive Psychotherapy, 41(3), 280-289. doi:10.1017/S1352465812000240

Przeworski, A., Newman, M. G., Pincus, A. L., Kasoff, M. B., Yamasaki, A. S., Castonguay, L. G., \& Berlin, K. S. (2011). Interpersonal pathoplasticity in individuals with generalized anxiety disorder. Journal of abnormal psychology, 120(2), 286-298. doi: $10.1037 / \mathrm{a} 0023334$

Revicki, D. A., Travers, K., Wyrwich, K. W., Svedsater, H., Locklear, J., Mattera, M. S., . . . Montgomery, S. (2012). Humanistic and economic burden of generalized anxiety disorder in North America and Europe. Jornal of Affective Disorders, 140(2), 103-112. doi:10.1016/j.jad.2011.11.014

Richards, D., Richardson, T., Timulak, L., \& McElvaney, J. (2015). The efficacy of internet-delivered treatment for generalized anxiety disorder: A systematic review and meta-analysis. Internet Interventions, 2(3), 272-282. doi:doi.org/10.1016/j.invent.2015.07.003

Richards, D., Timulak, L., Rashleigh, C., McLoughlin, O., Colla, A., Joyce, C., . . . Anderson-Gibbons, M. (2016). Effectiveness of an internetdelivered intervention for generalized anxiety disorder in routine care: A randomised controlled trial in a student population. Internet 
$\begin{array}{lll}\text { Interventions, } & \text { 6(Supplement } & \mathrm{C}),\end{array}$ doi:doi.org/10.1016/j.invent.2016.10.003

Roemer, L., \& Orsillo, S. M. (2002). Expanding our conceptualization of and treatment for generalized anxiety disorder: Integrating mindfulness/acceptance-based approaches with existing cognitivebehavioral models. Clinical Psychology: Science and Practice, 9(1), 54-68. doi:10.1093/clipsy/9.1.54

Roemer, L., \& Orsillo, S. M. (2007). An open trial of an acceptance-based behavior therapy for generalized anxiety disorder. Behavior Therapy, $38(1), 72-85$

Roemer, L., Orsillo, S. M., \& Salters-Pedneault, K. (2008). Efficacy of an acceptance-based behavior therapy for generalized anxiety disorder: evaluation in a randomized controlled trial. Journal of Consulting and Clinical Psychology, 76(6), 1083-1089.

Rozental, A., Kottorp, A., Boettcher, J., Andersson, G., \& Carlbring, P. (2016). Negative effects of psychological treatments: an exploratory factor analysis of the negative effects questionnaire for monitoring and reporting adverse and unwanted events. Plos One, 11(6), e0157503-e0157503. doi:10.1371/journal.pone.0157503

Rozental, A., Magnusson, K., Boettcher, J., Andersson, G., \& Carlbring, P. (2017). For better or worse: An individual patient data meta-analysis of deterioration among participants receiving Internet-based cognitive behavior therapy. Journal of Consulting and Clinical Psychology, 85(2), 160-177. doi:10.1037/ccp0000158

Ruiz, F. J., Peña-Vargas, A., Ramírez, E. S., Suárez-Falcón, J. C., GarcíaMartín, M. B., García-Beltrán, D. M., . . . Sánchez, P. D. (2020). Efficacy of a two-session repetitive negative thinking-focused acceptance and commitment therapy (ACT) protocol for depression and generalized anxiety disorder: a randomized waitlist control trial. Psychotherapy, 57(3), 444-456. doi:10.1037/pst0000273

Ruscio, A. M., Chiu, W. T., Roy-Byrne, P., Stang, P. E., Stein, D. J., Wittchen, H.-U., \& Kessler, R. C. (2007). Broadening the definition of generalized anxiety disorder: effects on prevalence and associations with other disorders in the national comorbidity survey replication. Journal of Anxiety Disorders, 21(5), 662-676. doi:10.1016/j.janxdis.2006.10.004

Schafer, J. L., \& Graham, J. W. (2002). Missing data: our view of the state of the art. Psychological methods, 7(2), 147-177.

Serowik, K. L., Roemer, L., Suvak, M., Liverant, G., \& Orsillo, S. M. (2020). A randomized controlled pilot study evaluating Worry Less, Live More: The Mindful Way Through Anxiety Workbook. Cognitive Behaviour Therapy, 1-13. 
Sheehan, D. V., Lecrubier, Y., Sheehan, K. H., Amorim, P., Janavs, J., Weiller, E., . . . Dunbar, G. C. (1998). The Mini-International Neuropsychiatric Interview (M.I.N.I.): the development and validation of a structured diagnostic psychiatric interview for DSMIV and ICD-10. The Journal of clinical psychiatry, 59 Suppl 20, 2233; quiz 34-57.

Silverberg, F. (2005). Make the leap : a practical guide to breaking the patterns that hold you back: Marlowe \& Co.

Springer, K. S., Levy, H. C., \& Tolin, D. F. (2018). Remission in CBT for adult anxiety disorders: a meta-analysis. Clinical Psychology Review, 61, 1-8. doi:doi.org/10.1016/j.cpr.2018.03.002

Stefan, S., Cristea, I. A., Szentagotai Tatar, A., \& David, D. (2019). Cognitive-behavioral therapy (CBT) for generalized anxiety disorder: Contrasting various CBT approaches in a randomized clinical trial. Journal of Clinical Psychology, 75(7), 1188-1202. doi:10.1002/jclp.22779

Sunderland, M., Wong, N., Hilvert-Bruce, Z., \& Andrews, G. (2012). Investigating trajectories of change in psychological distress amongst patients with depression and generalised anxiety disorder treated with internet cognitive behavioural therapy. Behaviour Research and Therapy, 50(6), 374-380. doi:10.1016/j.brat.2012.03.005

Szkodny, L. E., Newman, M. G., \& Goldfried, M. R. (2014). Clinical experiences in conducting empirically supported treatments for generalized anxiety disorder. Behavior Therapy, 45(1), 7-20. doi:10.1016/j.beth.2013.09.009

Thompson, E. M., Destree, L., Albertella, L., \& Fontenelle, L. F. (2020). Internet-based acceptance and commitment therapy: a transdiagnostic systematic review and meta-analysis for mental health outcomes. Behavior Therapy. doi:doi.org/10.1016/j.beth.2020.07.002

Titov, N., Andersson, G., \& Paxling, B. (2016). ICBT in psychiatry: Generalised anxiety disorder. In N. Lindefors \& G. Andersson (Eds.), Guided internet-based treatments in psychiatry. (pp. 79-100). Cham: Springer International Publishing.

Titov, N., Andrews, G., Robinson, E., Schwencke, G., Johnston, L., Solley, K., \& Choi, I. (2009). Clinician-assisted Internet-based treatment is effective for generalized anxiety disorder: randomized controlled trial. Australian and New Zealand Journal of Psychiatry, 43(10), 905-912. doi:10.1080/00048670903179269

Titov, N., Dear, B. F., Staples, L. G., Terides, M. D., Karin, E., Sheehan, J., . . . McEvoy, P. M. (2015). Disorder-specific versus transdiagnostic and clinician-guided versus self-guided treatment for major depressive disorder and comorbid anxiety disorders: a randomized 
controlled trial. Journal of Anxiety Disorders, 35, 88-102. doi:10.1016/j.janxdis.2015.08.002

Tyrer, P., \& Baldwin, D. (2006). Generalised anxiety disorder. The Lancet, 368(9553), 2156-2166. doi:doi.org/10.1016/S0140-6736(06)69865-6

Vlaescu, G., Alasjö, A., Miloff, A., Carlbring, P., \& Andersson, G. (2016). Features and functionality of the Iterapi platform for internet-based psychological treatment. Internet Interventions, 6, 107-114. doi:10.1016/j.invent.2016.09.006

Waller, G., \& Turner, H. (2016). Therapist drift redux: why well-meaning clinicians fail to deliver evidence-based therapy, and how to get back on track. Behaviour Research and Therapy, 77, 129-137. doi:10.1016/j.brat.2015.12.005

Wells, A. (1995). Meta-cognition and worry: a cognitive model of generalized anxiety disorder. Behavioural and Cognitive Psychotherapy, 23(3), 301-320. doi:10.1017/S1352465800015897

Wittchen, H.-U. (2002). Generalized anxiety disorder: prevalence, burden, and cost to society. Depression And Anxiety, 16(4), 162-171. doi:doi.org/10.1002/da.10065

Yonkers, K. A., Bruce, S. E., Dyck, I. R., \& Keller, M. B. (2003). Chronicity, relapse, and illness--course of panic disorder, social phobia, and generalized anxiety disorder: findings in men and women from 8 years of follow-up. Depression and Anxiety, 17(3), 173-179. doi:10.1002/da.10106 



\section{Papers}

The papers associated with this thesis have been removed for copyright reasons. For more details about these see:

http://urn.kb.se/resolve?urn=urn:nbn:se:liu:diva-170049 


\section{LINKÖPING STUDIES IN BEHAVIOURAL SCIENCE}

196. EKEBLAD, ANNIKA. A Randomized Trial of Interpersonal Psychotherapy and Cognitive Behavioral Therapy for Major Depressive Disorder Predictors of process and outcome. 2016. ISBN: 978-91-7685-803-5

197. MÅNSSON, KRISTOFFER N.T. Restructuring the Socially Anxious Brain. Using magnetic resonance imaging to advance our understanding of effective cognitive behaviour therapy for social anxiety disorder. 2016. ISBN: 978-91$7685-688-8$

198. SILFVERNAGEL, KRISTIN. Individually tailored internet-based cognitive behavioural therapy for adolescents, young adults and older adults with anxiety. 2017. ISBN: 978-91-7685-566-9

199. ELOFSSON, JESSICA. Children's early mathematics learning and development. Number game interventions and number line estimations. 2017. ISBN: 978-91-7685-517-1

200. ÅHLFELDT, EMANUEL. Hållbart utvecklingsarbete i vård och omsorg. Ett institutionellt perspektiv på projekt i en professionell och byråkratisk kontext. 2017. ISBN: 978-91-7685-445-7

201. VERNMARK, KRISTOFER. Therapeutic alliance and different treatment formats when delivering internet-based CBT for depression. 2017. ISBN: 978-91-7685-436-5

202. FRANKL, MY. Psychotherapy for Substance Use Disorder - the importance of affects. 2017. ISBN: 978-91-7685-429-7

203. ABDULLA, AFRAH. Readiness or resistance? - Newly arrived adult migrants' experiences, meaning making, and learning in Sweden. 2017. ISBN: 978-91-7685-428-0

204. OLSSON, LINDA. “Count on me!". Mathematical development, developmental dyscalculia and computer-based intervention. 2018. ISBN: 978-91-7685-409-9

205. COLLIANDER, HELENA, Being and Becoming a Teacher in Initial Literacy and Second Language Education for Adults. 2018. ISBN: 978-91-7685-304-7

206. TOPOOCO, NAIRA. Blended Cognitive Behavior Therapy. Efficacy and Acceptability for Treating Depression in the Adult and Adolescent Population. 2018. ISBN: 978-91-7685-297-2

207. SOLÍS MARCOS, IGNACIO. Challenges in Partially Automated Driving: A Human Factors Perspective. 2018. ISBN: 978-91-7685-296-5 
208. THORSTEN, ANJA. Berättelseskrivande i skolan. Att studera, beskriva och utveckla ett kunnande. 2018. ISBN: 978-91-7685-258-3

209. ELEONOR, BREDLÖV EKNOR. Shaped for beauty. Vocational and gendered subjectivities in private education for the beauty industry.

210. VESTERGREN, SARA. Psychological change as an outcome of participation in collective action. 2018. ISBN:978-91-7685-242-2

211. MÖLLER, CLARA. Mentalizing. Competence and process. 2018. ISBN: 978-91-7685-189-0

212. SÖDERBERG GIDHAGEN, YLVA. Psychological treatment of outpatients with substance use disorders in routine care - attachment style, alliance, and treatment outcome. 2018. ISBN: 978-91-7685-197-5

213. HAGMAN, WILLIAM. When are nudges acceptable? Influences of beneficiaries, techniques, alternatives and choice architects. 2018. ISBN: 97891-7685-160-9

214. RAHM, LINA. Educational imaginaries: a genealogy of the digital citizen. 2019. ISBN: 978-91-7685-158-6

215. HALVARSSON LUNDQVIST, AGNETA. Learning Dynamics of Workplace Development Programmes. Studies in Swedish national programmes. 2019. ISBN: 978-91-7685-124-1

216. HOLMQVIST LARSSON, MATTIAS. Rupture and Repair in the Working Alliance: Relation to Psychotherapy Outcome and Within-Session Interaction. 2019. ISBN: 978-91-7685-111-1

217. LINDQVIST, HENRIK. Student teachers' and beginning teachers' coping with emotionally challenging situations. 2019. ISBN: 978-91-7685-078-7

218. GRÖNLUND, AGNETA. Återkoppling i analoga och digitala klassrum. Spänningsfyllda verksamheter i samhällskunskapsundervisning. 2019. ISBN: 978-91-7685-074-9

219. ÅKERBLOM, ERIKA. Utbildning och hälsa i nationens intresse. Styrningsteknologier och formering av en förädlad befolkning. 2019. ISBN: 978-91-7685-053-4220.

220. ÖSTERBORG WIKLUND, SOFIA. Folkbildning i global (o)rättvisa. Makt och motstånd i folkhögskolans internationalisering och transnationella kurser. 2019. ISBN: 978-91-7519-002-0 


\section{FACULTY OF ARTS AND SCIENCES}

Linköping Studies in Arts and Sciences No. 794, 2020

Linköping Studies in Behavioural Science No. 221, 2020

Department of Behavioural Sciences and Learning

Linköping University

SE-581 83 Linköping, Sweden

www.liu.se 